Document downloaded from:

http://hdl.handle.net/10251/47660

This paper must be cited as:

Altarejos García, L.; Escuder Bueno, I.; Serrano Lombillo, AJ.; Gómez De Membrillera Ortuño, M. (2012). Methodology for estimating the probability of failure by sliding in concrete gravity dams in the context of risk analysis. Structural Safety. 34(1):1-13. doi:10.1016/j.strusafe.2012.01.001.

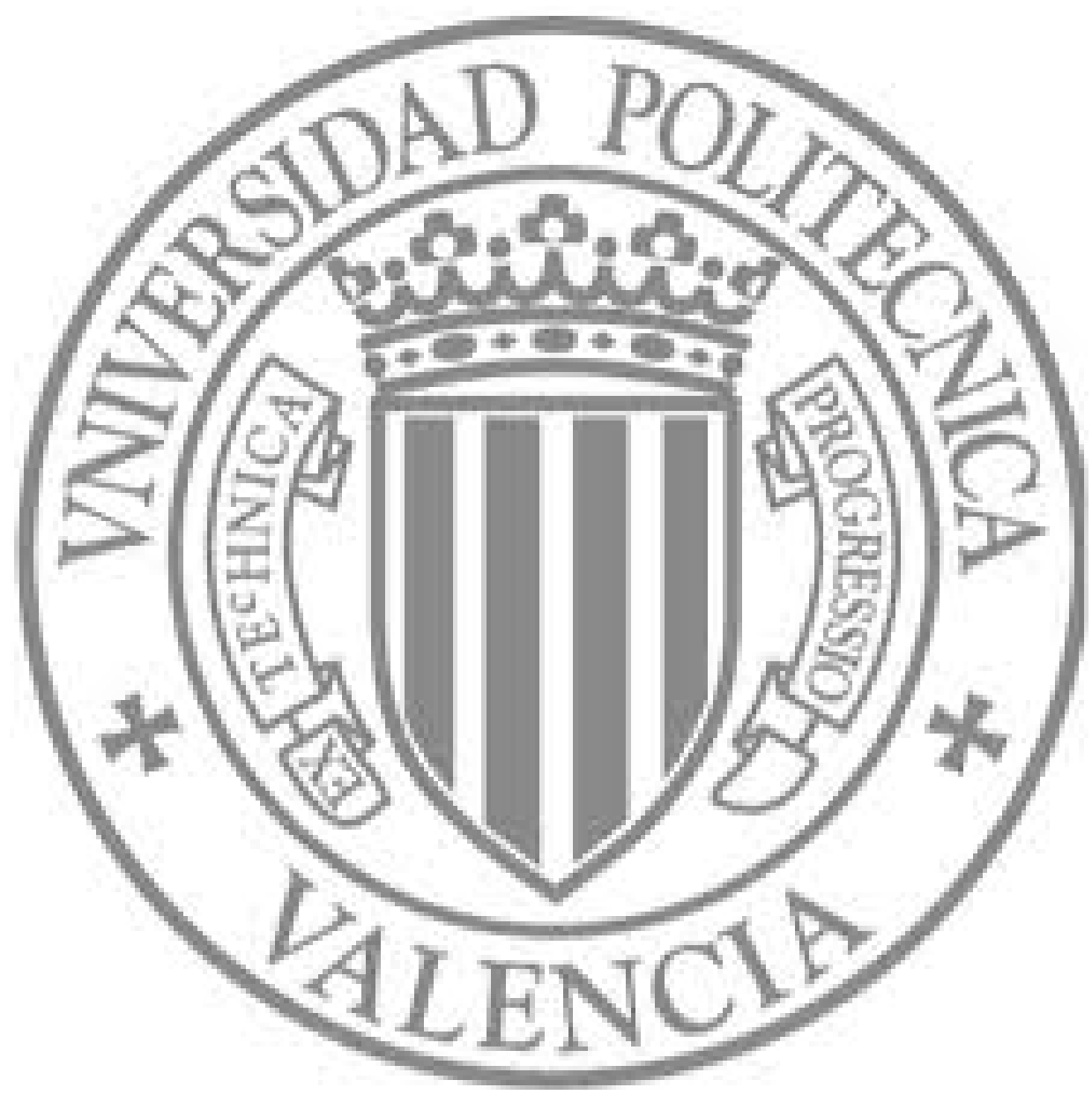

The final publication is available at

http://dx.doi.org/10.1016/j.strusafe.2012.01.001

Copyright Elsevier 


\title{
METHODOLOGY FOR ESTIMATING THE PROBABILITY OF FAILURE BY SLIDING IN CONCRETE GRAVITY DAMS IN THE CONTEXT OF RISK ANALYSIS
}

\author{
January $12^{\text {th }}, 2012$
}

\begin{abstract}
Dam safety based on risk analysis methodologies demand quantification of the risk of the dam-reservoir system. This means that, for a given initial state of the system, and for the several failure modes considered, it is necessary to estimate the probability of the load events and the conditional probability of response of the system for a given load event, as well as estimating the consequences on the environment for the obtained response of the system. The following paper focuses in the second of these probabilities, that is, quantifying the conditional probability of response of the system, for a given load event, and for the specific case of concrete gravity dams. Dam-reservoir systems have a complex behavior which has been tackled traditionally by simplifications in the formulation of the models and adoption of safety factors. The purpose of the methodology described in this paper is to improve the estimation of the conditional probability of response of the damreservoir system for concrete gravity dams, using complex behavior models based on numerical simulation techniques, together with reliability techniques of different levels of precision are applied, including Level 3 reliability techniques with Monte Carlo simulation. The paper includes an example of application of the proposed methodology to a Spanish concrete gravity dam, considering the failure mode of sliding along the rock-concrete interface. In the context of risk analysis, the results obtained for conditional probability of failure allow several conclusions related to their validity and safety implications that acquire a significant relevance due to the innovation of the study performed.
\end{abstract}




\section{Introduction}

Risk related to dam safety can be defined as follows "Measure of the probability and severity of an adverse effect to life, health, property, or environment. In the general case, risk is estimated by the combined impact of all triplets of scenario, probability of occurrence and the associated consequence" [1]. Therefore, equation (1) describes how risk is quantified:

$$
\text { Risk }=\int \mathrm{P}(\text { load events }) \times \mathrm{P}(\text { response } \mid \text { loads }) \times \mathrm{C}(\text { loads, response })
$$

where the symbol " " "represents the conditional probability. Application of Risk Analysis to dams requires identification of potential failure modes and quantification of the conditional probability of the system's response for the different given load events. This estimation can be done rigorously through the "probability analysis", using statistical techniques to obtain the probability of failure, $\mathrm{P}_{\mathrm{f}}$, computed by equation (2):

$$
P_{f}\left[g^{*}\left(x_{1}, x_{2}, \ldots, x_{n}\right) \leq 0\right]=\int_{g^{*}\left(x_{1}, x_{2}, \ldots, x_{n}\right) \leq 0} f_{X_{1}, X_{2}, \ldots, X_{n}}\left(x_{1}, x_{2}, \ldots, x_{n}\right) d x_{1} d x_{2} \ldots d x_{n}
$$

where $\mathrm{x}_{1}, \mathrm{x}_{2}, \ldots, \mathrm{x}_{\mathrm{n}}$ are the random variables in the problem (geometry, materials, loads, etc.), $\mathrm{g}^{*}\left(\mathrm{x}_{1}, \mathrm{x}_{2}, \ldots, \mathrm{x}_{\mathrm{n}}\right)$ is the performance function, with the failure condition defined as $\mathrm{g}^{*} \leq 0$ and $\mathrm{f}_{\mathrm{X} 1, \mathrm{X} 2, \ldots, \mathrm{Xn}}$ : is the joint probability density function for the ' $\mathrm{n}$ ' random variables.

Normally, these statistical techniques or structural reliability measurements are classified in three levels. Level 1 Method (Partial Safety Factors) does not provide the probability of failure and the uncertainty is tackled through safety factors for different loading conditions. Level 2 Methods approximate the joint probability density function $\mathrm{f}_{\mathrm{X} 1, \mathrm{X} 2, \ldots, \mathrm{Xn}_{\mathrm{n}}}\left(\mathrm{x}_{1}, \mathrm{x}_{2}, \ldots, \mathrm{x}_{\mathrm{n}}\right)$ through its first two moments (mean and standard deviation). In some situations, an approximation is also used for the performance function $\mathrm{g}^{*}\left(\mathrm{x}_{1}, \mathrm{x}_{2}, \ldots, \mathrm{x}_{\mathrm{n}}\right)$. Level 3 Methods provide the probability of failure using the joint probability density function together with specific methods of integration.

As long as the probability of failure is always associated with a given "failure mode", the correct formulation of the latter is a key issue to ensure the soundness of the solutions obtained with the methodology. Table 1 includes a summary of a series of phenomena that need to be considered in the characterization of dam behavior (and consequently in the potential failure modes) for concrete dams [2]. Once the characterization of the behavior that can lead to the ultimate failure of the structure is done, the analysis methods have a high level of complexity, allowing the use of advanced non linear constitutive models, fracture mechanics models, and dynamic analysis techniques in the non linear time domain, as it has been shown in several benchmarks over the years [3-6]. These models require the knowledge of a high number of parameters whose exact values cannot be immediately determined and frequently they are based upon scarce data, coming from similar published cases.

Reliability techniques have been applied frequently to other kind of problems in the geotechnical field, such as slope stability, where probabilistic analysis has received considerable attention [7-14]. 
Table 1

Phenomena related with the evaluation of the safety of concrete dams [2]

\begin{tabular}{|c|c|c|c|}
\hline TYPE & PHENOMENON & $\begin{array}{l}\text { MODELED } \\
\text { ELEMENTS }\end{array}$ & INDICATOR \\
\hline \multirow{4}{*}{ STRUCTURAL } & Sliding and overturning & Dam & Rigid body equilibrium \\
\hline & Slope or blocks instability & $\begin{array}{l}\text { Foundation } \\
\text { Reservoir }\end{array}$ & Rigid body equilibrium \\
\hline & Stress-strain condition & $\begin{array}{c}\text { Dam } \\
\text { Foundation }\end{array}$ & $\begin{array}{c}\text { Displacement - Strain - Stresses - } \\
\text { Movement of joints }\end{array}$ \\
\hline & $\begin{array}{l}\text { Global and local stability } \\
\text { related with cracks }\end{array}$ & $\begin{array}{c}\text { Dam } \\
\text { Foundation }\end{array}$ & $\begin{array}{c}\text { Opening - Length } \\
\text { Propagation potential - Depth }\end{array}$ \\
\hline \multirow{2}{*}{ DEGRADATION } & $\begin{array}{c}\text { Ageing, } \\
\text { alkali-aggregate reactions } \\
\end{array}$ & Dam & Variation of mechanical properties \\
\hline & Dissolution by filtration & Foundation & Variation of mechanical properties \\
\hline \multirow{6}{*}{ HYDRAULIC } & Sedimentation & $\begin{array}{l}\text { Dam } \\
\text { Outlet }\end{array}$ & Transport of solids \\
\hline & Filtration & $\begin{array}{c}\text { Foundation } \\
\text { Reservoir }\end{array}$ & Pressures - Velocities - Flow \\
\hline & $\begin{array}{c}\text { Erosion at the toe of the } \\
\text { dam }\end{array}$ & $\begin{array}{c}\text { Dam } \\
\text { Foundation }\end{array}$ & $\begin{array}{c}\text { Flows } \\
\text { Kinetic energy }\end{array}$ \\
\hline & Erosion at the spillway & Spillway & Pressures \\
\hline & Erosion & Outlet & Velocities - Contents of solid material \\
\hline & Cavitation & Outlet & Pressure \\
\hline
\end{tabular}

\section{Description of the space of analysis}

The methodology for estimating probabilities of failure proposed in this paper requires a preliminary clarification of the term "analysis space", i.e., the current state of knowledge in the two following fields: on the one hand, the (deterministic) methods of structural analysis for dams and, on the other hand, the mathematical models of structural reliability analysis.

After a review of the state of the art on deterministic methods for structural analysis for dams [2, 15-17] a qualitative classification has been developed in which, for every group of models identified according to their complexity in an increasing order from $\mathrm{A}$ to $\mathrm{H}$, a differentiation is made according to the type of constitutive model used for the dam and foundation. Three groups are considered: 0 (rigid body, corresponding to a limit equilibrium analysis), 1 (deformable solid, linear and elastic), 2 (deformable solid, with non elastic models). Table 2 shows the full classification. A space of analysis can be defined for concrete dams based on two vectors: structural analysis methods ( $\mathrm{X}$-axis) and reliability methods (Y-axis), as it is shown of Fig. 1. The horizontal and vertical arrows in the previous figure present the development trends followed by the knowledge in each of their corresponding fields individually, and a diagonal arrow indicates the direction followed in this research, combining advanced analysis methods for the behavior of concrete dams with structural reliability methods, in order to obtain better estimates of the probability of failure in the risk analysis context. 
Table 2

Levels of deterministic analysis for the study of the structural response of dams.

\begin{tabular}{|c|c|c|c|c|c|}
\hline $\begin{array}{l}\text { Type of } \\
\text { model }\end{array}$ & $\begin{array}{c}\text { Dominion } \\
\text { models } \\
\text { Dam-foundation }\end{array}$ & $\begin{array}{c}\text { Interconnection } \\
\text { with Hydro- } \\
\text { mechanic } \\
\text { phenomena }\end{array}$ & Flow dominion & $\begin{array}{c}\text { Constitutive } \\
\text { model in the } \\
\text { dam-foundation } \\
\text { domain }\end{array}$ & Level \\
\hline \multirow{19}{*}{$2 \mathrm{D} / 3 \mathrm{D}$} & \multirow{11}{*}{$\begin{array}{l}\text { Continuous models } \\
\text { with previously } \\
\text { defined interfaces }\end{array}$} & \multirow{6}{*}{$\begin{array}{l}\text { Not } \\
\text { interconnected }\end{array}$} & \multirow{3}{*}{$\begin{array}{l}\text { Flow only along the } \\
\text { discontinuities }\end{array}$} & Rigid solid & A0 \\
\hline & & & & Elastic & A1 \\
\hline & & & & Plastic & $\mathrm{A} 2$ \\
\hline & & & \multirow{3}{*}{$\begin{array}{c}\text { Flow in the whole } \\
\text { domain }\end{array}$} & Rigid solid & B0 \\
\hline & & & & Elastic & B1 \\
\hline & & & & Plastic & B2 \\
\hline & & \multirow{5}{*}{ Interconnected } & \multirow{3}{*}{$\begin{array}{l}\text { Flow only along the } \\
\text { discontinuities }\end{array}$} & Rigid solid & $\mathrm{C} 0$ \\
\hline & & & & Elastic & $\mathrm{C} 1$ \\
\hline & & & & Plastic & $\mathrm{C} 2$ \\
\hline & & & \multirow{2}{*}{$\begin{array}{c}\text { Flow in the whole } \\
\text { domain }\end{array}$} & Pore-elastic & D1 \\
\hline & & & & Pore-elastic & D2 \\
\hline & \multirow{8}{*}{$\begin{array}{c}\text { Fracture mechanics } \\
\text { models }\end{array}$} & \multirow{4}{*}{$\begin{array}{c}\text { Not } \\
\text { interconnected }\end{array}$} & \multirow{2}{*}{$\begin{array}{l}\text { Flow only along the } \\
\text { discontinuities }\end{array}$} & LEFM & E1 \\
\hline & & & & NLFM & E2 \\
\hline & & & \multirow{2}{*}{$\begin{array}{c}\text { Flow in the whole } \\
\text { domain }\end{array}$} & LEFM & F1 \\
\hline & & & & NLFM & F2 \\
\hline & & \multirow{4}{*}{ Interconnected } & \multirow{2}{*}{$\begin{array}{l}\text { Flow only along the } \\
\text { discontinuities }\end{array}$} & LEFM & G1 \\
\hline & & & & NLFM & G2 \\
\hline & & & \multirow{2}{*}{$\begin{array}{c}\text { Flow in the whole } \\
\text { domain }\end{array}$} & LEFM & H1 \\
\hline & & & & NLFM & $\mathrm{H} 2$ \\
\hline
\end{tabular}

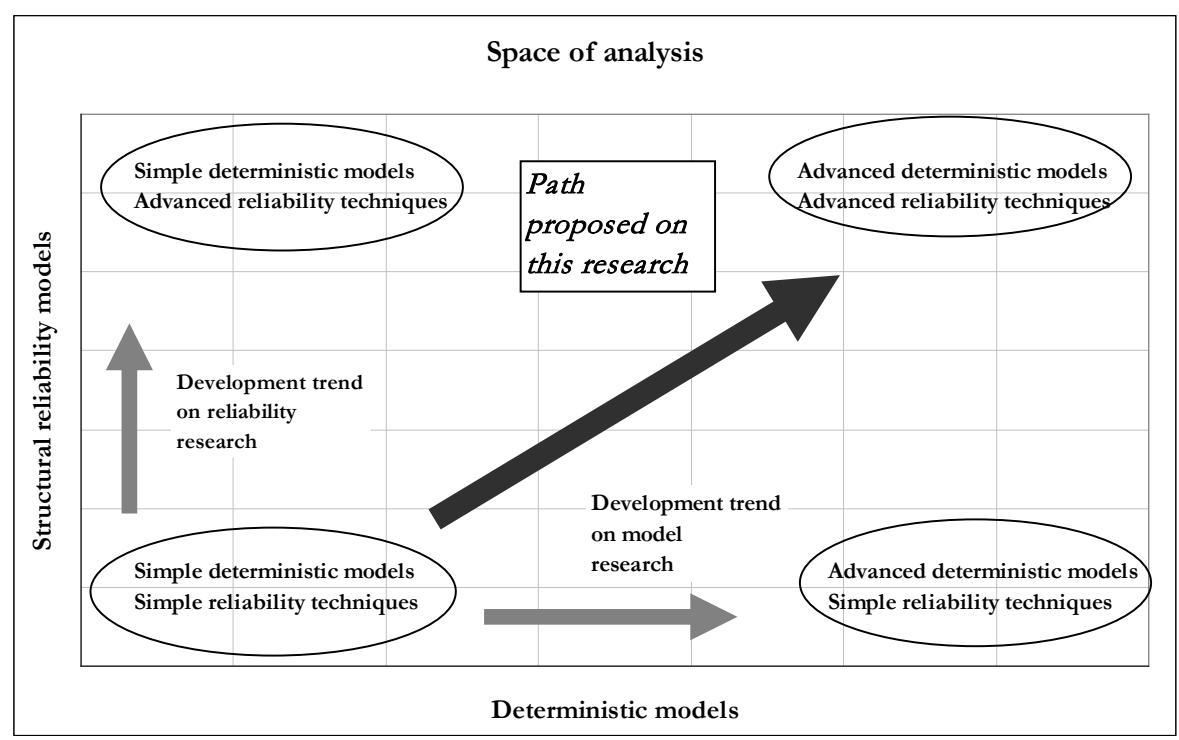

Fig. 1. Space of structural and reliability analysis for dams 


\section{Proposed methodology}

The methodology described herein is applied to a concrete gravity dam for a single failure mode defined as "sliding along the dam-foundation contact". It is consider that its application to any other type of dam and for any other failure mode, particularly for those of essentially "structural" nature, can be carried out rather straightforwardly due to its generic formulation. The methodology is divided in five phases that are described below and reflected in Fig. 2.

\subsection{Defining the Base Model and the Advanced Model}

The starting point, Step 0, should always be the existence of a General Risk Model fully defined and complete for the concrete dam, including the definition of the loading scenarios and the identification of all possible failure modes. Step 1 is the definition of the Base and Advanced Models for the analysis of the failure mode under consideration. The Base Model should be a mathematical model such that failure can be expressed in terms of a mathematical performance function. The Advanced Model can be a numerical model implemented in a simulation code, and it does not necessarily have to express the failure in terms of an explicit mathematical performance function.

\subsection{Analysis of variables}

Step 2 is the analysis of variables (loads and parameters) that appear in the problem. The variables are classified whether as determined variables, whose values are known with very little uncertainty, or as random variables, whose values are not known with precision and their knowledge is, therefore, reliant on uncertainty. For the variables considered as random, it is necessary to find out which are their probability distribution functions. In order to assess the probability distributions of the variables, results of research, tests and all the information available from the assessment of the dam should be taken into account.

\subsection{Reliability analysis on the Base Model}

In Step 3 a Level 1 reliability analysis is carried out on the Base Model. Before running any probabilistic analysis it is convenient to obtain the safety factors for the Base Model, allowing a first verification of the model and establishing a first frame of reference in which to lay out the results obtained in the successive phases.

In Step 4 a Level 2 reliability analysis is carried out on the Base Model. In this step the probabilistic calculations as such are initiated. Application on the Base Model of three Level 2 methods is done in a sequential manner: First Order Second Moment (FOSM) Taylor's Method, Point Estimate Method and the Advance Second Moment (ASM) Hasofer-Lind Method. FOSM Taylor's Method [18] is applied in order to obtain an initial estimation of the conditional probabilities of failure, and to determine the contribution of each variable to the variance of the performance function. Point Estimate Method [19] is applied to capture the influence of the skewness of the probability distributions on the estimate of the probability of failure. It should be noted that this method is not good when the number of random variables is large [20]. An Advanced Second Moment method [21] is used to determine the feasible ranges in which the achievement of probabilities makes mathematical sense, which encloses the field of application of Level 3 methods needed later and that are more exact but demand for higher calculation effort. 


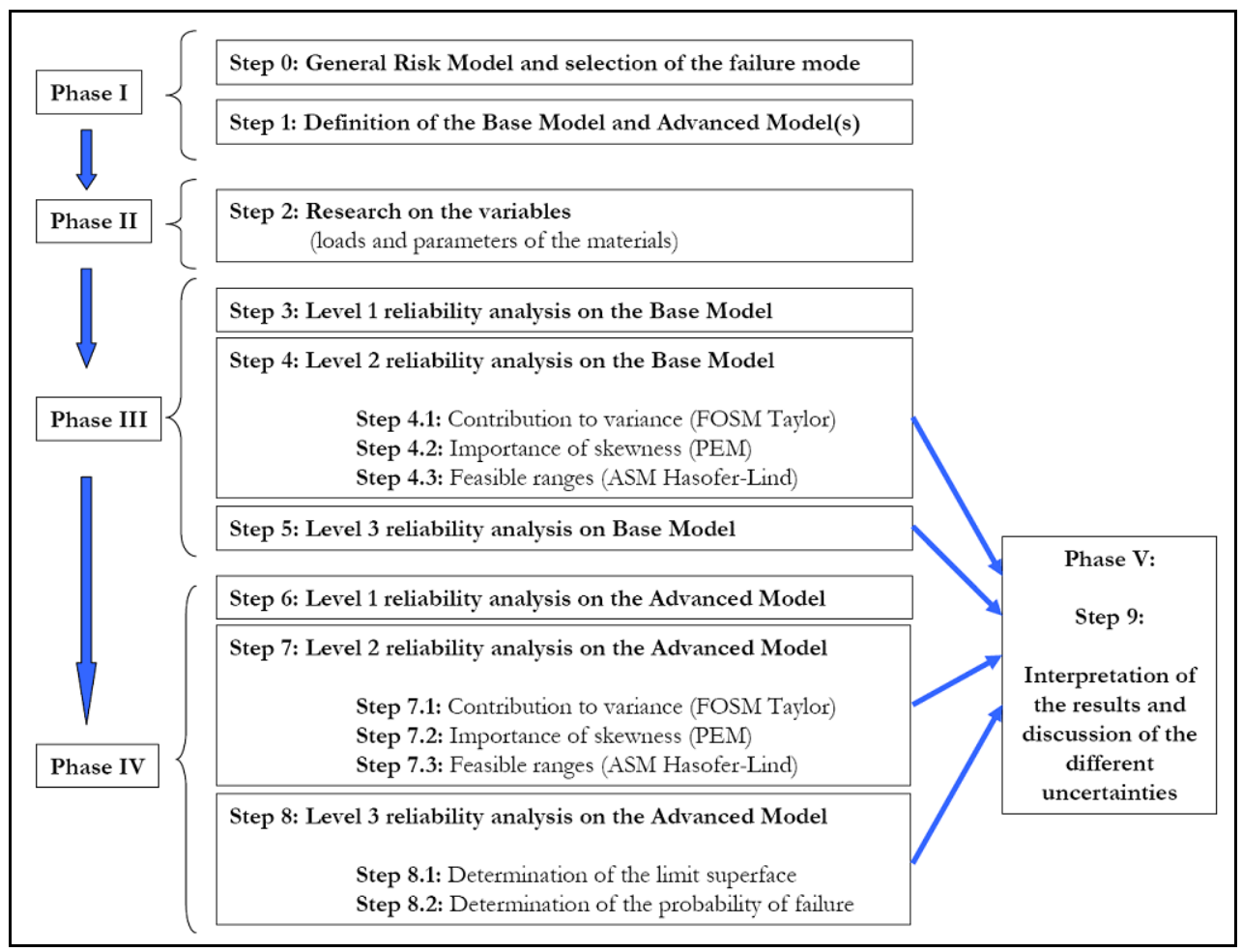

Fig. 2. Flow chart for estimation of probability of failure of concrete dams in Risk Analysis

In Step 5 a Level 3 reliability analysis is carried out on the Base Model. Once the random variables with a higher contribution to the variance of the performance function have been identified, and considering all the other variables as fixed variables with given values, a Level 3 reliability analysis is run on the Base Model to provide a more exact estimate of the probability of failure. Of all possible Level 3 techniques the methodology proposes the Monte Carlo method, for its ease of application in problems formulated in terms of a performance function [22]. The probability of failure, $\mathrm{P}_{\mathrm{f}}$, is estimated according to (3).

$$
\hat{P_{f}} \approx \frac{N_{f}}{N}
$$

where $\hat{P}_{f}$ is the estimation of the probability of failure; $\mathrm{N}_{\mathrm{f}}$ is the number of simulations where failure occurred and $\mathrm{N}$ is the total number of simulations. The number of Monte Carlo simulations performed should be large enough to capture the searched probability. The probability to capture one or more failures, $\mathrm{P}_{\mathrm{N}}$, with $\mathrm{N}$ trials if the searched probability is $\mathrm{P}_{\mathrm{f}}$, assuming a Poisson distribution is given by (4).

$$
P_{N}=1-e^{-N \cdot P_{f}}
$$


The number of trials, $\mathrm{N}$, needed to achieve a probability, $\mathrm{P}$, that the absolute error, $\varepsilon$, defined as the absolute value of the difference between the estimated probability of failure and the true probability of failure has a value of $\mathrm{P}\left[\left|\hat{P}_{f}-\mathrm{P}_{\mathrm{f}}\right|<\varepsilon\right]=1-\delta$ is given approximately by (5), as can be seen in [23].

$$
N \approx \frac{P_{f}\left(1-P_{f}\right)}{\delta \varepsilon^{2}}
$$

\subsection{Reliability analysis on the Advanced Model}

As it has been done with the Base Model, before trying to run a purely probabilistic analysis, first the classical safety factors are obtained for the Advanced Model in Step 6. This allows for a preliminary verification and comparison between both models, which is very useful for the evaluation of possible needs for improvement or refinement of the models, or even to completely rule out its use. In Step 7, if the Advanced Model allows the formulation or evaluation of a performance function, Level 2 methods are applied the same way as it was described in Step 4. Next, in Step 8, an estimate on the conditional probability of failure is done applying the Level 3 reliability techniques on the Advanced Model. If the Advanced Model includes random variables that the Base Model does not consider, and if it is not possible to apply FOSM Taylor's method to check the contribution of each variable to the variance of the problem, then a sensitivity analysis should be performed to identify the variables that should be consider as random. The proposed Level 3 technique is the Monte Carlo Method [24].

Running the great number of simulations required by this technique can make its practical application unfeasible, bearing in mind the calculation times associated with the use of complex tools in numerical simulation. The concept of limit state surface is proposed to avoid this problem $[\mathbf{2 4}, \mathbf{2 5}]$. The limit state or response surface (a.k.a. limit hyper-surface in an n-dimensional situation, ' $\mathrm{n}$ ' being the number of random variables considered) sets the boundary between the safe and failure domains corresponding to the Advanced Model. This limit state surface is defined using the numerical model in order to obtain a number of points on it. Then, a statistical adjustment is performed to get the best estimate of the surface position and shape from the given points. Once the Limit Surface is obtained as described previously, it is no longer necessary the use of the numerical simulation tool to calculate the probability of failure since it is enough to generate samples from the probability distributions of the random variables with the Monte Carlo techniques, verifying how many of them lay in the failure domain. This way, a value for the conditional probability of failure of the dam is estimated, based on a more realistic model than the Base Model.

\subsection{Interpretation of the results}

The last step of the methodology, Step 9, focuses on critical interpretation of the results obtained for the probability searched, bearing in mind the nature and the treatment given to the different uncertainties involved in the analysis $[23,26]$. 


\section{4.- Application to a case study.}

\subsection{Description of the dam}

Next, the methodology is applied to a case study corresponding to a Spanish concrete gravity dam for the hydrologic scenario. The failure mode considered is sliding along the contact for the spillway section. The cross section where the spillway is located presents a triangular profile, with slopes of $0.05 / 0.75(\mathrm{U} / \mathrm{D})$. The height of the cross section is $73 \mathrm{~m}$ above the foundation (the crest of the spillway is at an elevation of $313 \mathrm{~m}$, the foundation level is at an elevation of $240 \mathrm{~m}$ ). The length of the crest of the dam is 198 meters, having an elevation of $322.50 \mathrm{~m}$. The water levels considered in the reservoir and their annual exceedance probabilities are shown in Table 3 and Fig. 3, according to Membrillera [27].

Table 3

Water levels considered and annual exceedance probabilities

\begin{tabular}{ccc}
\hline Water level (m.a.s.1.) & $\begin{array}{c}\text { Height over } \\
\text { foundation }(\mathrm{m})\end{array}$ & $\begin{array}{c}\text { Annual } \\
\text { Exceedance } \\
\text { Probability }\end{array}$ \\
\hline 268.00 & 28.00 & 1.0 \\
300.00 & 60.00 & $8.01 \times 10^{-1}$ \\
313.00 (spillway crest) & 73.00 & $5.56 \times 10^{-1}$ \\
320.00 (Normal Pool Level) & 80.00 & $3.57 \times 10^{-1}$ \\
322.50 (top of the dam) & 82.50 & $3.23 \times 10^{-4}$ \\
326.00 & 86.00 & $1.20 \times 10^{-6}$ \\
331.70 & 91.70 & $4.00 \times 10^{-9}$ \\
\hline
\end{tabular}

\subsection{Base Model and the Advanced Model of the dam (Step 1)}

The models used, in accordance with the classification described in the previous sections, are all of type $\mathrm{A}(2 \mathrm{D}$ analysis, with predefined discontinuities, non interconnected hydromechanic analysis and flow domain restricted to the discontinuities). The model A0 (Limit Equilibrium) is two-dimensional, with the geometry shown in the Fig. 3, with a single interface in the contact between the dam and the foundation. This interface can mobilize tensile strength up to some extent. The sliding resistance can be defined through a MohrCoulomb model, as a function of the friction angle and cohesion.

The A1 model comprises a deformable body model, where both dam and foundation are deformable elastic solids. The two-dimensional code on finite differences FLAC 2D (Itasca Consulting Group, Inc., 1994) has been used, allowing the simulation of the behavior of the continuous mechanics, including the interaction phenomena. The code uses a lagrangian procedure with an explicit resolution of the movement equations, with references to the deformed mesh. The resolution assumes a two-dimensional state of plane strain. Each element of the model is subjected to its own stress-strain relation, previously defined. The model is completed with the applied forces and the corresponding boundary conditions. Two regions are defined in the model: dam and foundation, together with the interface between them, as it is shown in Fig. 4. 


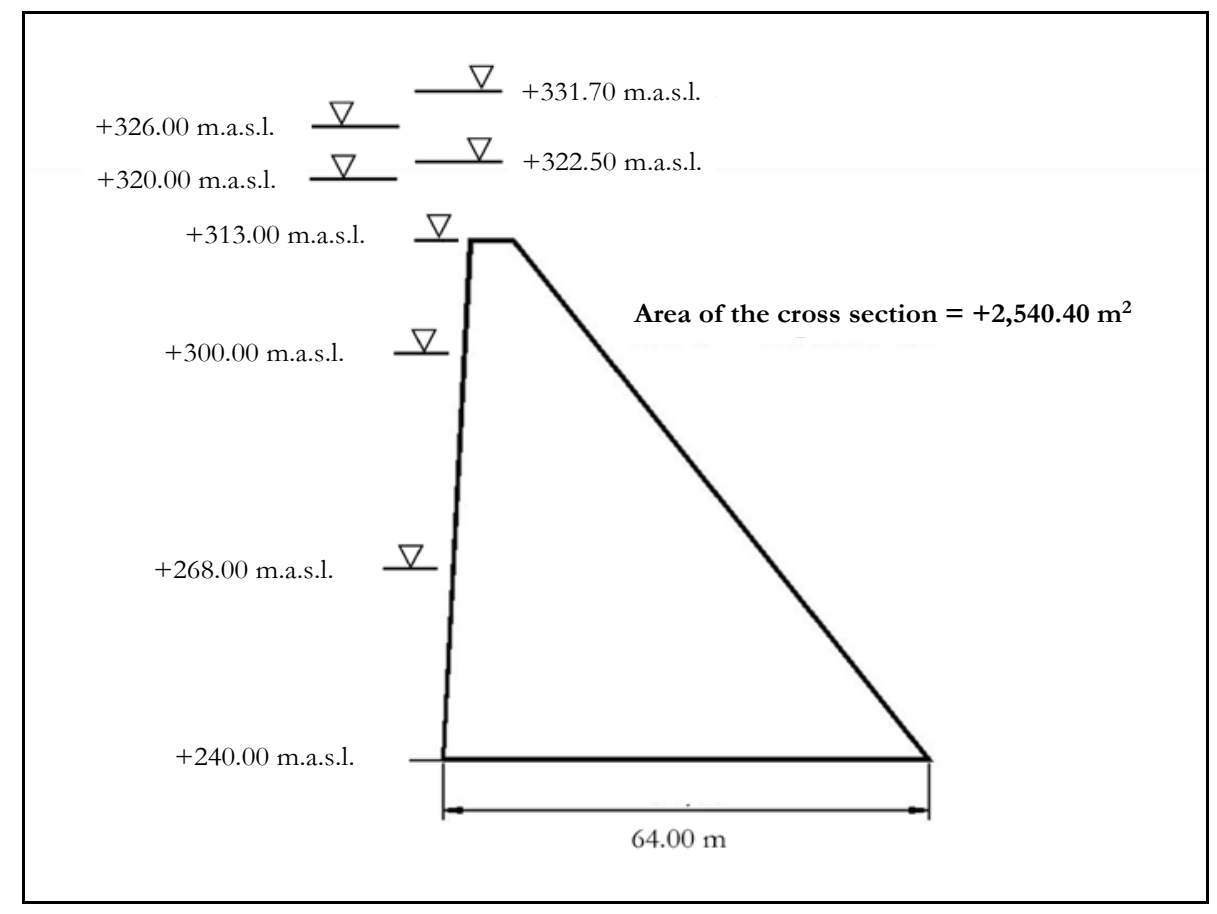

Fig. 3. Simplified spillway section of the dam and water levels considered

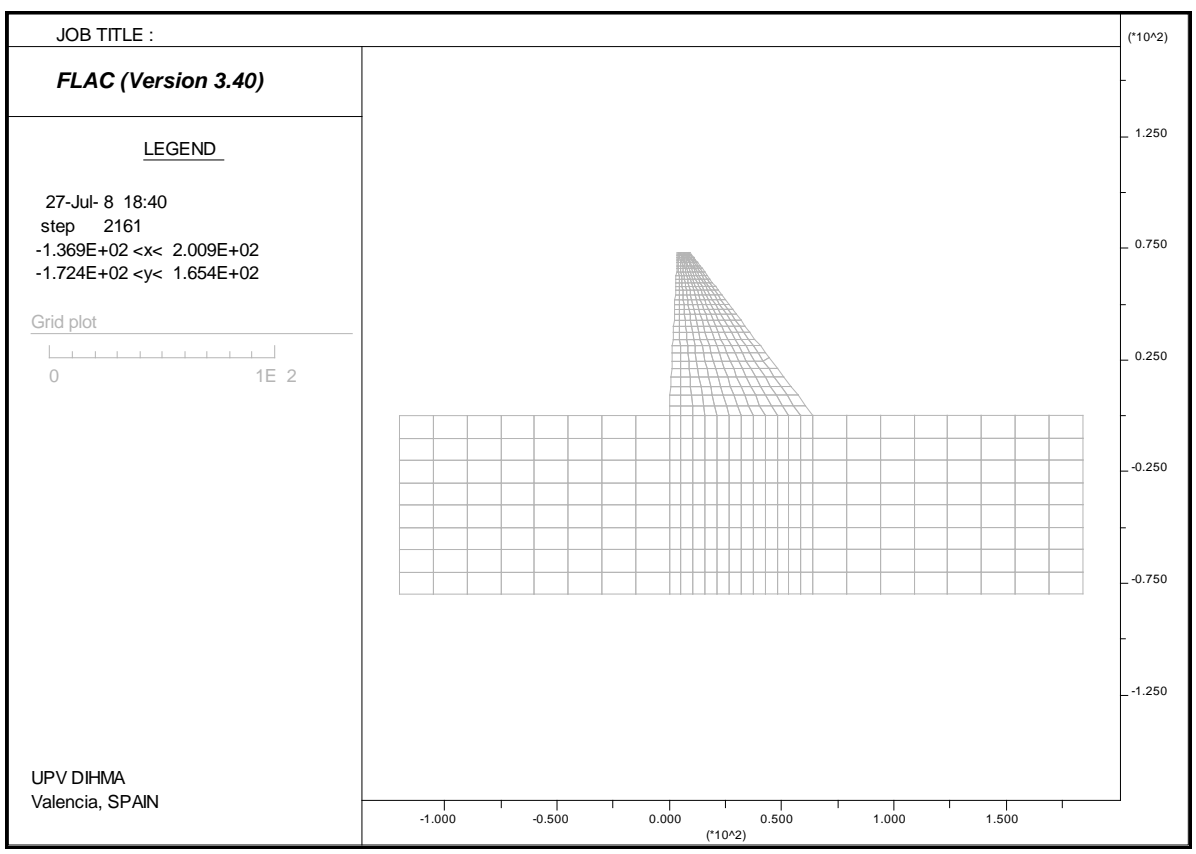

Fig. 4. Geometric model. Calculation grid of the spillway section. 
The foundation is stretched out upstream and downstream a horizontal distance of $120 \mathrm{~m}$ from the bottom of the dam and is $80 \mathrm{~m}$ deep under the base plane of the dam. A grid has been created trying to reach a compromise between the necessity of avoiding unrealistic stress concentrations and ensuring a minimum density in the mesh, especially along the dam-foundation contact, aiming to reproduce a possible crack opening and propagation. The model allows for crack opening and propagation along the interface with uplift updating. The selected grid is shown in the figure below. A similar model was tested and validated using the case study for a gravity dam proposed in 1999 ICOLD Benchmark Workshop [3]. The model was able to reproduce the stress filed at the contact between dam and foundation and the results obtained matched quite accurately the results given with other simulation tools [28].

\subsection{Analysis of variables (Step 2)}

The 10 random variables chosen are shown in Table 4. These variables were all initially assumed to be uncorrelated [29]. It should be noted that some of the variables have large uncertainties due to the lack of data. This is the case of the drain ineffectiveness $(K)$, the coefficient of uplift increase above Normal Pool Level $(\alpha)$, the specific weight of the sediments $\left(\gamma_{\text {sed }}\right)$, the height of the sediments $\left(\mathrm{H}_{\text {sed }}\right)$ and the sediments pressure coefficient $\left(\mathrm{K}_{\text {sed }}\right)$. These uncertainties justify the use of probability distributions such as the uniform or the triangular with large coefficients of variation [20]. For the other five random variables, some information is available from the dam site, so more common probability distributions in geomechanical practice such as the Normal or the lognormal have been used. In particular, for shear strength parameters of the Mohr-Coulomb model, the Normal distribution is used for the friction angle and the lognormal distribution is used for the cohesion, as these are the distributions that fit best the available data. This result is similar to others found in literature $[12,14,17,30]$. The detailed justification of the process of selection of the probability distributions and parameters for each random variable can be found in Altarejos [28].

Regarding the assumption of uncorrelation between random variables, it should be noticed that cohesion and friction angle variables present potential negative correlation due to the linear approximation of the curved failure envelope to Mohr circles. This negative correlation can be assessed by means of laboratory tests with normal stresses varying on a relatively wide range. However, the normal stress acting on the concrete-rock interface of a dam varies on a much narrower range, depending on the geometry of the dam, so this potential correlation is less evident [31]. It should be also considered that rock of different quality may be present along the contact, thus adding variability to friction angle and cohesion correlation.

The impact of correlation on probability of failure has been studied elsewhere [28] and the results show that negative correlation decreases the probability of failure, as sampling of low values of one parameter is accompanied by an increased probability of sampling high values of the other, which somehow compensates for the strength reduction. The probability of sampling at the same time two low values for both variables is less if they are negatively correlated than if they are assumed to be uncorrelated. From this point of view, assuming that cohesion and friction angle are not correlated is somehow a conservative approach. 
Table 4

Selected random variables.

\begin{tabular}{|c|c|c|c|c|c|c|}
\hline Variable & Unit & $\begin{array}{l}\text { Probability } \\
\text { function }\end{array}$ & Mean & $\begin{array}{l}\text { Standard } \\
\text { deviation }\end{array}$ & $\begin{array}{c}\text { Min } \\
\text { value }\end{array}$ & $\begin{array}{c}\text { Max } \\
\text { value }\end{array}$ \\
\hline Concrete density $\left(\rho_{c}\right)$ & $\mathrm{Kg} / \mathrm{m}^{3}$ & Normal & 2350 & 49.67 & 2150 & 2550 \\
\hline $\begin{array}{l}\text { Drain ineffectiveness } \\
\text { coefficient }(\mathrm{K})\end{array}$ & - & Triangular & 0.37 & 0.22 & 0.00 & 1.00 \\
\hline $\begin{array}{l}\text { Coefficient of uplift increase } \\
\text { above Normal Pool Level }(\alpha)\end{array}$ & - & Uniform & 0.50 & 0.29 & 0.00 & 1.00 \\
\hline $\begin{array}{l}\text { Specific weight of the } \\
\text { sediments }\left(\gamma_{\text {sed }}\right)\end{array}$ & $\mathrm{N} / \mathrm{m}^{3}$ & Triangular & $873.3 \mathrm{~g}$ & $98.7 \mathrm{~g}$ & $650 \mathrm{~g}$ & $1130 \mathrm{~g}$ \\
\hline Height of the sediments $\left(\mathrm{H}_{\text {sed }}\right)$ & M & Uniform & 7.75 & 4.47 & 0.00 & 15.50 \\
\hline $\begin{array}{l}\text { Sediments pressure coefficient } \\
\qquad\left(\mathrm{K}_{\mathrm{sed}}\right)\end{array}$ & - & Triangular & 0.415 & 0.035 & 0.333 & 0.500 \\
\hline $\begin{array}{l}\text { Compression strength of the } \\
\text { rock mass }\left(\sigma_{\mathrm{cm}}\right)\end{array}$ & $\mathrm{MPa}$ & Lognormal & 9.06 & 0.60 & 0 & $+\infty$ \\
\hline $\begin{array}{l}\text { Friction angle in the dam- } \\
\text { foundation contact }(\varphi)\end{array}$ & o & Normal & 50 & 8.79 & 30 & 70 \\
\hline $\begin{array}{l}\text { Cohesion in the dam- } \\
\text { foundation contact (c) }\end{array}$ & $\mathrm{MPa}$ & Lognormal & 0.418 & 0.298 & 0.00 & 2.00 \\
\hline $\begin{array}{l}\text { Tensile strength in the dam- } \\
\text { foundation contact }\left(\sigma_{i, t}\right)\end{array}$ & $\mathrm{MPa}$ & Normal & 0.90 & 0.22 & 0.00 & 1.80 \\
\hline
\end{tabular}

\subsection{Reliability analysis on the Base Model (Steps 3-5)}

In order to run the Level 1 analysis the mean values of the variables were taken. The safety factors obtained for each of the levels of reservoir are shown in Fig. 5. Through the use of FOSM Taylor's Method with the ten random variables described in Step 2 and for the pool levels considered, the order of magnitude of the conditional probability of failure as well as the weight of the different random variables in this estimate has been obtained, as it is shown in Table 5 and in Figs. 6-7. 


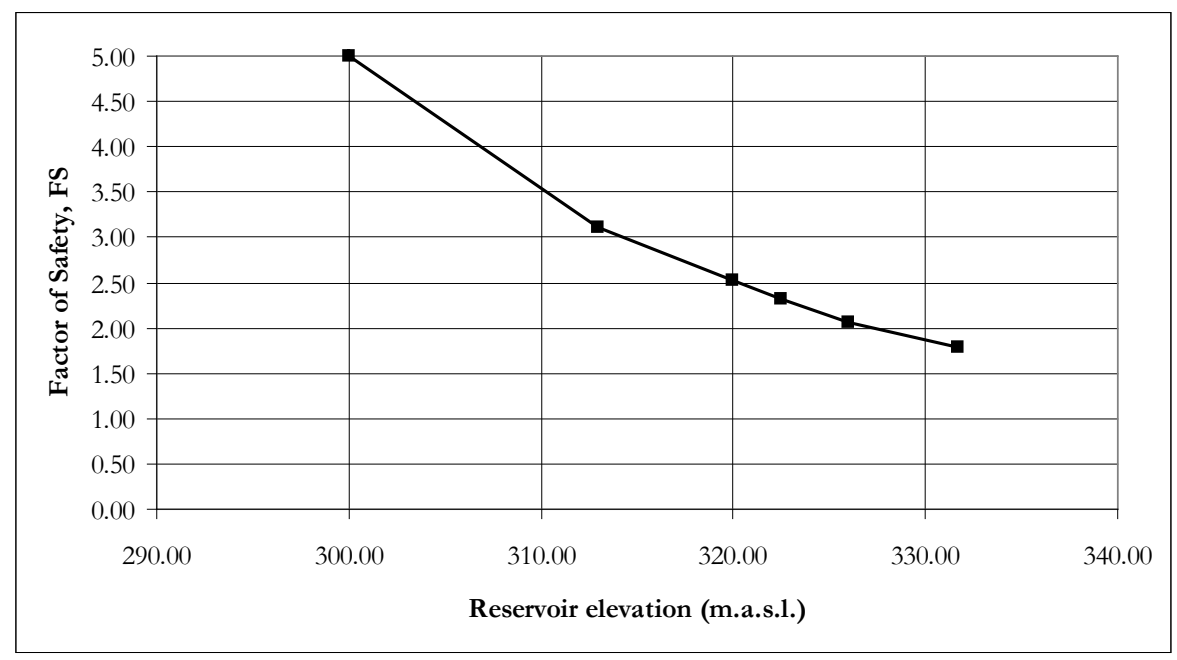

Fig. 5. Base Model. Safety factors as a function of the level of the reservoir.

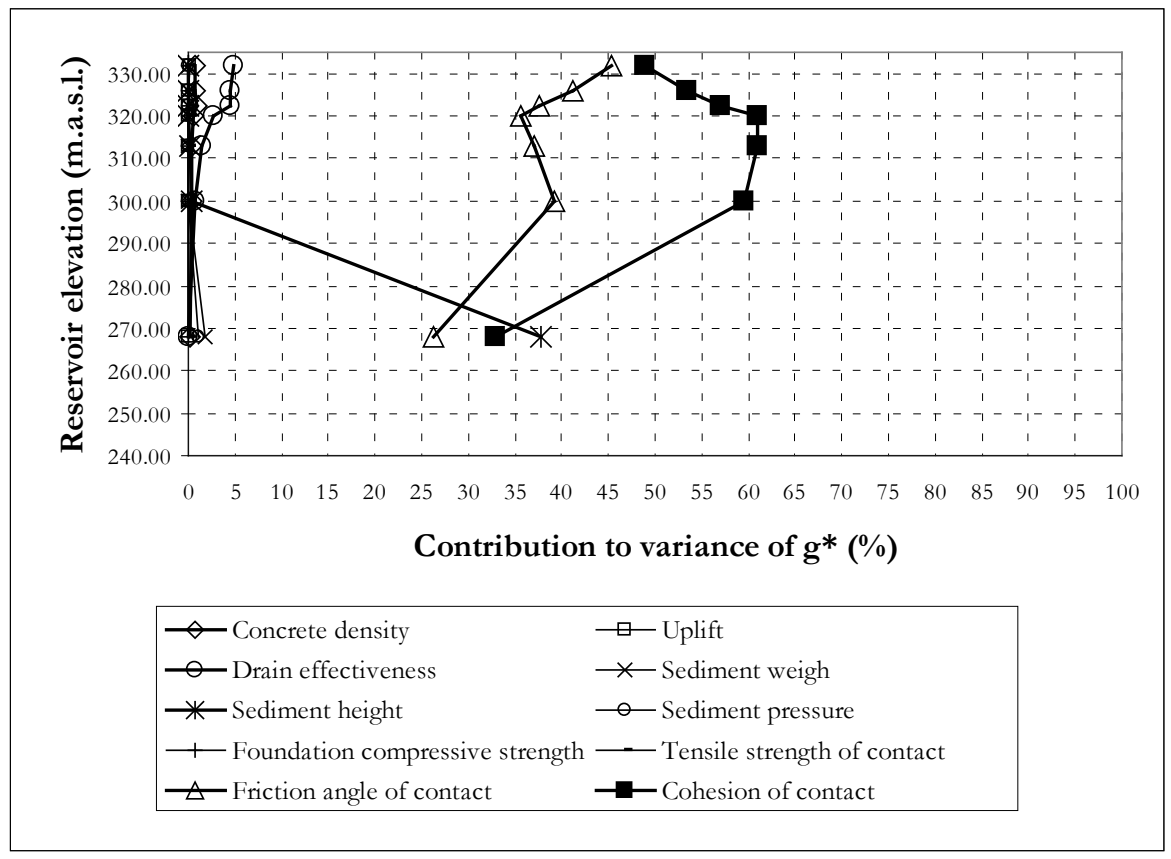

Fig. 6. Base Model with FOSM Taylor's Method. Contribution of the random variables to the variance of the performance function 
Table 5

Base Model with FOSM Taylor's Method. Probabilities of failure considering 10 random variables.

\begin{tabular}{cccccc}
\hline $\begin{array}{c}\text { Upstream } \\
\text { level } \\
\text { (m.a.s.1.) }\end{array}$ & $\begin{array}{c}\text { Downstream } \\
\text { level } \\
\text { (m.a.s.1.) }\end{array}$ & $\begin{array}{c}\text { Mean value } \\
\text { of } \mathbf{g}^{*}\end{array}$ & $\begin{array}{c}\text { Standard } \\
\text { deviation of } \\
\mathbf{g}^{*}\end{array}$ & $\begin{array}{c}\text { Reliability } \\
\text { index }\end{array}$ & $\begin{array}{c}\text { Conditional probability } \\
\text { of failure }\end{array}$ \\
\hline $\mathrm{n}_{1}$ & $\mathrm{n}_{2}$ & $\mathrm{E}\left[\mathrm{g}^{*}\right]$ & $\sigma_{\mathrm{g}^{*}}$ & $\beta$ & $\mathrm{P}_{\mathrm{f}}$ \\
\hline 300.00 & 266.00 & 4.00 & 1.66 & 2.41 & $8.08 \times 10^{-3}$ \\
313.00 & 266.00 & 2.11 & 1.05 & 2.01 & $2.20 \times 10^{-2}$ \\
320.00 & 266.00 & 1.52 & 0.86 & 1.77 & $3.83 \times 10^{-2}$ \\
322.50 & 266.00 & 1.32 & 0.79 & 1.67 & $4.70 \times 10^{-2}$ \\
326.00 & 266.00 & 1.07 & 0.69 & 1.55 & $6.03 \times 10^{-2}$ \\
331.70 & 266.00 & 0.78 & 0.58 & 1.33 & $9.10 \times 10^{-2}$ \\
\hline
\end{tabular}

Table 6

Base Model with FOSM Taylor's Method. Conditional probability of failure for 2 random variables.

\begin{tabular}{|c|c|c|c|c|c|}
\hline $\begin{array}{c}\text { Upstream } \\
\text { level } \\
\text { (m.a.s.l.) }\end{array}$ & $\begin{array}{c}\text { Downstream } \\
\text { level } \\
\text { (m.a.s.l.) }\end{array}$ & $\begin{array}{c}\text { Mean } \\
\text { value of } g^{*}\end{array}$ & $\begin{array}{c}\text { Standard } \\
\text { deviation of } \\
\mathrm{g}^{*}\end{array}$ & Reliability index & $\begin{array}{c}\text { Conditional } \\
\text { probability of failure }\end{array}$ \\
\hline $\mathrm{n}_{1}$ & $\mathrm{n}_{2}$ & $\mathrm{E}\left[\mathrm{g}^{*}\right]$ & $\sigma_{\mathrm{g} *}$ & $\beta$ & $\mathbf{P}_{\mathrm{f}}$ \\
\hline 268.00 & 266.00 & 73.79 & 24.16 & 3.05 & $1.13 \times 10^{-3}$ \\
\hline 300.00 & 266.00 & 4.00 & 1.65 & 2.42 & $7.73 \times 10^{-3}$ \\
\hline 313.00 & 266.00 & 2.11 & 1.04 & 2.03 & $2.10 \times 10^{-2}$ \\
\hline 320.00 & 266.00 & 1.52 & 0.85 & 1.80 & $3.58 \times 10^{-2}$ \\
\hline 322.50 & 266.00 & 1.32 & 0.77 & 1.72 & $4.26 \times 10^{-2}$ \\
\hline 326.00 & 266.00 & 1.07 & 0.67 & 1.60 & $5.52 \times 10^{-2}$ \\
\hline 331.70 & 266.00 & 0.78 & 0.57 & 1.38 & $8.45 \times 10^{-2}$ \\
\hline
\end{tabular}

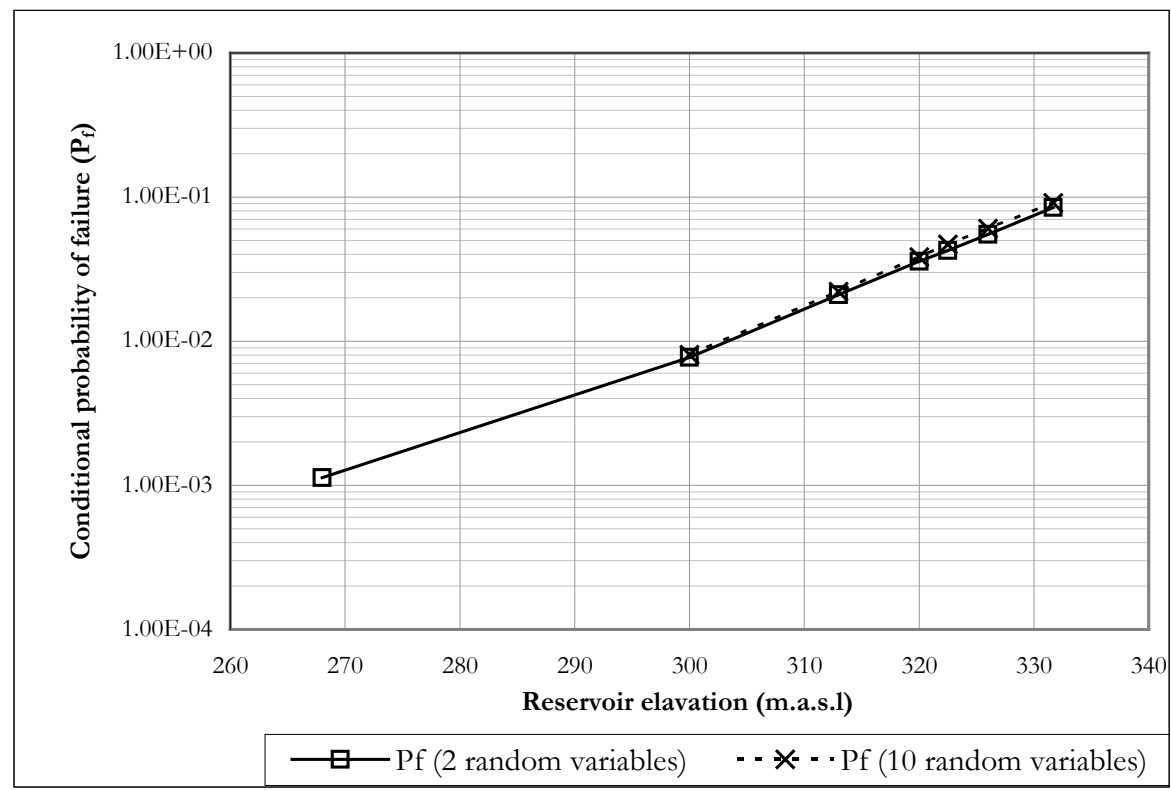

Fig. 7. Base Model with FOSM. Conditional probability of failure with 10 and 2 random variables. 
The variables with a higher contribution to the variance of the performance function are the friction angle and the cohesion along the dam-foundation contact. If the probability of failure is now calculated considering as random variables only these two, making the values of the rest constant and equal to their mean values, the probabilities obtained are very similar to those calculated with 10 random variables, as it is shown in Table 6 and in Fig. 7. Therefore, based on this result, the methodology will proceed considering the friction angle and the cohesion along the dam-foundation contact as the only random variables.

Using the Point Estimate Method, the magnitude of the influence of the skewness of the distributions on the estimation of the probability obtained in the previous step has been found. A second estimate of the probability of failure has been calculated as it is shown in Table 7 and in Fig. 8 and can be comparison between FOSM and PEM can be made. As it shown in Fig. 8, results are very similar in both cases.

Table 7

Base Model with Point Estimate Method. Probabilities of failure for 2 random variables.

\begin{tabular}{|c|c|c|c|c|c|}
\hline $\begin{array}{c}\text { Upstream } \\
\text { level } \\
\text { (m.a.s.l.) }\end{array}$ & $\begin{array}{l}\text { Downstream } \\
\text { level (m.a.s.1.) }\end{array}$ & $\begin{array}{c}\text { Mean } \\
\text { value of } g^{*}\end{array}$ & $\begin{array}{c}\text { Standard } \\
\text { deviation of } \mathrm{g}^{*}\end{array}$ & Reliability index & $\begin{array}{c}\text { Conditional probability } \\
\text { of failure }\end{array}$ \\
\hline $\mathrm{n}_{1}$ & $\mathbf{n}_{2}$ & $\mathrm{E}\left[\mathrm{g}^{*}\right]$ & $\sigma_{\mathrm{g} *}$ & $\beta$ & $\mathbf{P}_{\mathrm{f}}$ \\
\hline 268.00 & 266.00 & 76.76 & 24.16 & 3.18 & $7.44 \times 10^{-4}$ \\
\hline 300.00 & 266.00 & 4.19 & 1.65 & 2.54 & $5.58 \times 10^{-3}$ \\
\hline 313.00 & 266.00 & 2.22 & 1.04 & 2.15 & $1.59 \times 10^{-2}$ \\
\hline 320.00 & 266.00 & 1.62 & 0.85 & 1.91 & $2.79 \times 10^{-2}$ \\
\hline 322.50 & 266.00 & 1.41 & 0.77 & 1.84 & $3.31 \times 10^{-2}$ \\
\hline 326.00 & 266.00 & 1.15 & 0.67 & 1.72 & $4.29 \times 10^{-2}$ \\
\hline 331.70 & 266.00 & 0.85 & 0.57 & 1.50 & $6.64 \times 10^{-2}$ \\
\hline
\end{tabular}

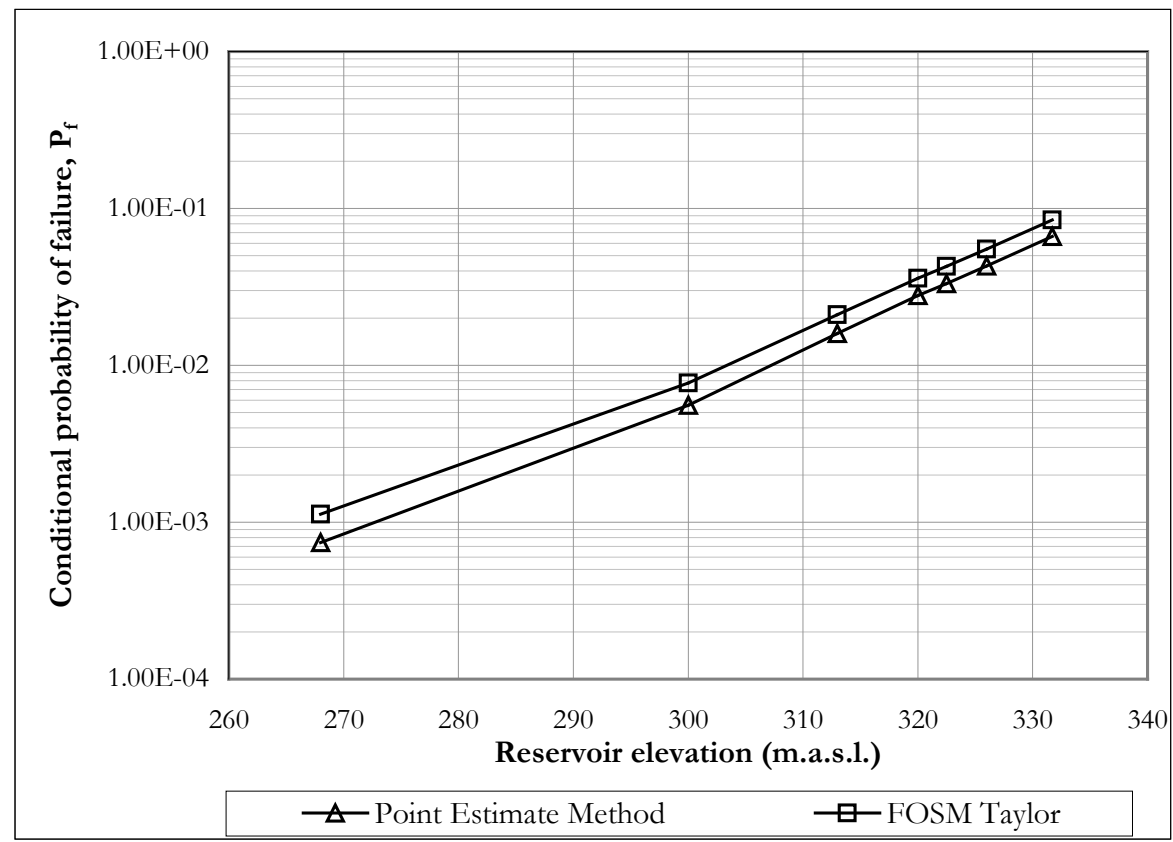

Fig. 8. Base Model with PEM and FOSM. Conditional probability of failure. 2 random variables. 
The application of the ASM Hasofer-Lind method has allowed the determination of a third estimate of the probability of failure, as it is shown in Table 8 and Fig. 9. Note that ASM allows identification of the feasible range of variation of water levels where estimation of probability makes mathematical sense. Both FOSM and Point Estimate Method are not able to capture this feature by themselves, as they do calculate values of probability even for low water levels, where the exact value of the probability is zero. As low water levels correspond to loading states with large probabilities of occurrence, large, false probabilities of failure are added to the overall risk model, leading to overestimation of the probability of failure.

Table 8

Base Model with ASM Hasofer-Lind Method. Probabilities of failure with 2 random variables.

\begin{tabular}{cccccc}
\hline $\begin{array}{c}\text { Upstream level } \\
(\mathbf{m} . \text { a.s.1.) }\end{array}$ & $\begin{array}{c}\text { Downstream } \\
\text { level (m.a.s.1.) }\end{array}$ & $\begin{array}{c}\text { Reliability } \\
\text { index }\end{array}$ & $\begin{array}{c}\text { Conditional } \\
\text { probability of failure }\end{array}$ & Design point \\
\hline $\mathbf{n}_{\mathbf{1}}$ & $\mathbf{n}_{\mathbf{2}}$ & $\boldsymbol{\beta}$ & $\mathbf{P f}$ & $\boldsymbol{\varphi}$ & $\mathbf{c}$ \\
\hline $268.00\left(^{*}\right)$ & 266.00 & - & 0.00 & - & - \\
$300.00\left(^{*}\right)$ & 266.00 & - & 0.00 & - & - \\
313.00 & 266.00 & 2.55 & $5.40 \times 10^{-3}$ & 31.29 & 0.00 \\
320.00 & 266.00 & 2.04 & $2.08 \times 10^{-2}$ & 37.01 & 0.00 \\
322.50 & 266.00 & 1.90 & $2.89 \times 10^{-2}$ & 38.78 & 0.00 \\
326.00 & 266.00 & 1.73 & $4.20 \times 10^{-2}$ & 41.13 & 0.00 \\
331.70 & 266.00 & 1.49 & $6.78 \times 10^{-2}$ & 42.48 & $5.38 \times 10^{4}$ \\
\hline
\end{tabular}

(*) For these levels, $g^{*} \leq 0$ is never reached for any point in the feasible region of values, therefore, the mathematical probability of failure is null

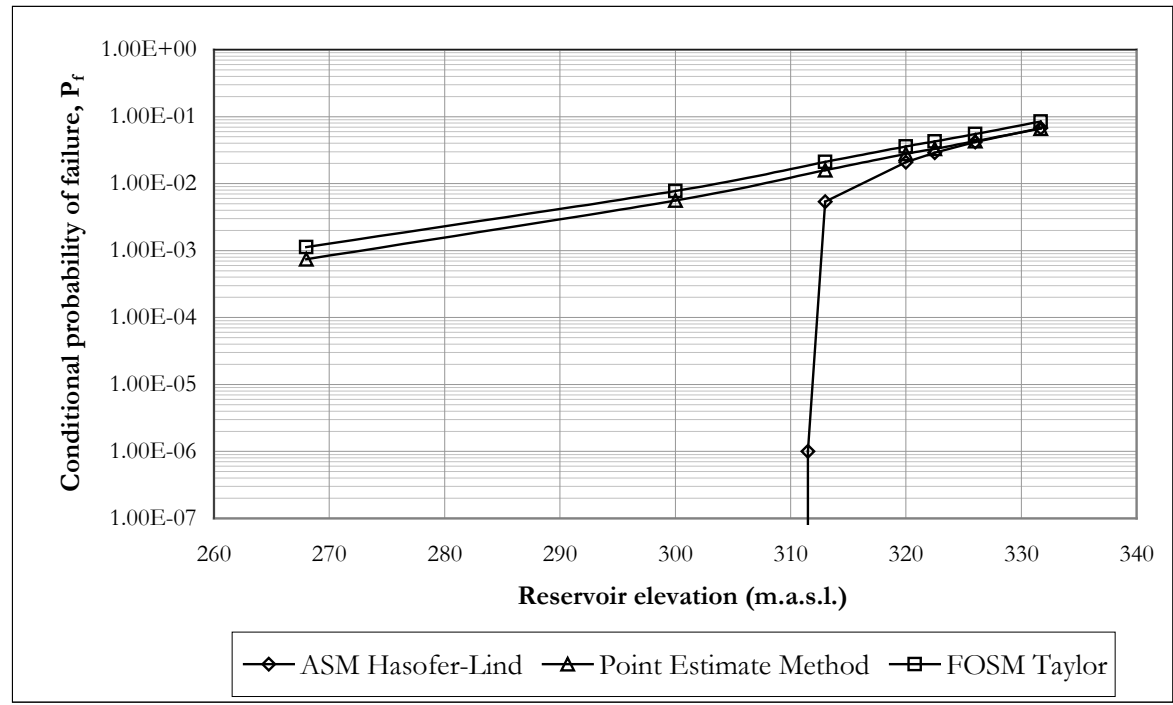

Fig. 9. Base Model with ASM Hasofer-Lind Method and other Level 2 methods. Conditional probability of failure for 2 random variables.

In the next step, a reliability analysis is done with the Monte Carlo simulation method, providing a more precise estimate of the probability of failure. Results are shown in Table 9 and in Fig. 10. 
It can be seen that identification of significant water levels with ASM helps reducing the number of cases to be analyzed with Monte Carlo simulation. Note also that when probabilities are low, a large number of simulations are needed to capture failure situations.

Table 9

Base Model with Level 3 Monte Carlo Method. Probabilities of failure for 2 random variables.

\begin{tabular}{cccccc}
\hline $\begin{array}{c}\text { Upstream level } \\
(\text { m.a.s.1.) }\end{array}$ & $\begin{array}{c}\text { Downstream } \\
\text { level (m.a.s.1.) }\end{array}$ & $\begin{array}{c}\text { Number of } \\
\text { samples }\end{array}$ & $\begin{array}{c}\text { Number of } \\
\text { failures }\end{array}$ & $\begin{array}{c}\text { Conditional } \\
\text { probability of } \\
\text { failure }\end{array}$ & $\begin{array}{c}\text { Standard } \\
\text { deviation of } \\
\mathbf{P}_{\mathbf{f}}\end{array}$ \\
\hline $\mathbf{n}_{1}$ & $\mathbf{n}_{2}$ & $\mathbf{N}$ & $\mathbf{N}_{\text {failures }}$ & $P_{f}=\frac{N_{\text {failures }}}{N}$ & $\sigma_{\hat{P}_{f}}$ \\
\hline 313.00 & 266.00 & $10,000,000$ & 0 & $<1.00 \times 10^{-7}$ & - \\
320.00 & 266.00 & 100,000 & 56 & $5.60 \times 10^{-4}$ & $7.48 \times 10^{-5}$ \\
322.50 & 266.00 & 10,000 & 16 & $1.60 \times 10^{-3}$ & $4.00 \times 10^{-4}$ \\
326.00 & 266.00 & 10,000 & 63 & $6.30 \times 10^{-3}$ & $7.91 \times 10^{-4}$ \\
331.70 & 266.00 & 10,000 & 320 & $3.20 \times 10^{-2}$ & $1.76 \times 10^{-3}$ \\
\hline
\end{tabular}

(*) For the 268 y $300 \mathrm{~m}$ levels, $g^{*} \leq 0$ is never reached for any point in the feasible region of values, therefore, the mathematical probability of failure is null

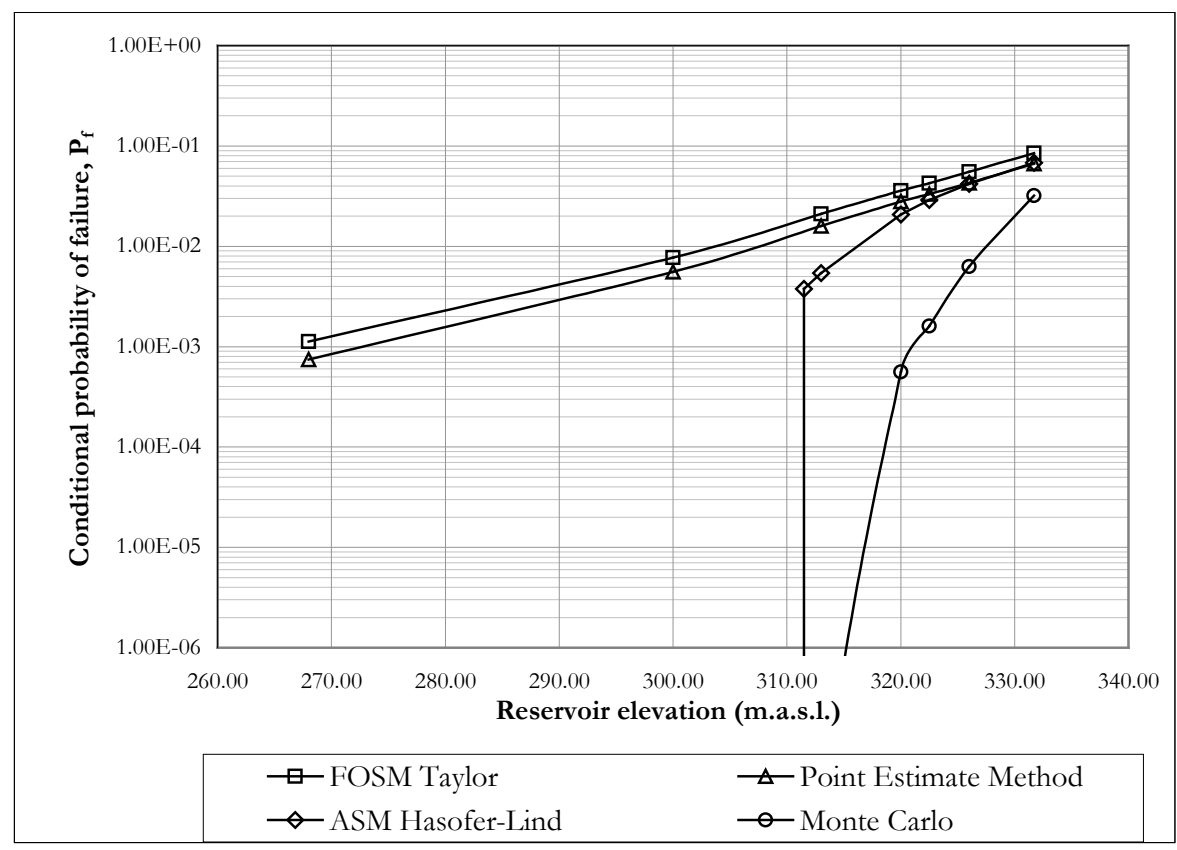

Fig. 10. Base Model with Level 3 Monte Carlo Method and Level 2 methods. Conditional probability of failure for 2 random variables.

\subsection{Reliability analysis on the Advanced Model (Steps 6-8)}

The stress-strain properties of the dam and foundation, the properties of the interface between dam and foundation and the main loads considered for the Advanced Model are summarized in Tables 10-11. 
Table 10

Variables considered in the elastic deformable solid model. Level 1.

\begin{tabular}{|c|c|c|c|}
\hline Region & Variable & Value & Comments \\
\hline \multirow{3}{*}{ Dam } & Density of concrete & $2350 \mathrm{~kg} / \mathrm{m}^{3}$ & Mean value \\
\hline & Elastic modulus & $15 \mathrm{GPa}$ & Value from tests \\
\hline & Poisson's ratio & 0.24 & Value from tests \\
\hline \multirow{3}{*}{ Foundation } & Density of concrete & $2350 \mathrm{~kg} / \mathrm{m}^{3}$ & Mean value \\
\hline & Elastic modulus & $5.45 \mathrm{GPa}$ & Mean value \\
\hline & Poisson's ratio & 0.26 & Mean from tests \\
\hline \multirow{3}{*}{$\begin{array}{l}\text { Dam-foundation } \\
\text { contact }\end{array}$} & Friction angle & $50^{\circ}$ & Mean peak value \\
\hline & Cohesion & $4.18 \times 10^{5} \mathrm{~Pa}$ & Mean peak value \\
\hline & Tensile strength & $9.00 \times 10^{5} \mathrm{~Pa}$ & Mean value \\
\hline
\end{tabular}

Table 11

Level 1 loads considered in the elastic deformable solid.

\begin{tabular}{|c|c|}
\hline Variable & Comments \\
\hline Hydraulic pressure & $\begin{array}{l}7 \text { reservoir levels corresponding to the hydrological scenario: 268, 300, 313, } \\
320 \text { (Normal Pool Level), 322.50, 326, } 331.70 \text { m.a.s.l. }\end{array}$ \\
\hline Uplift pressure & $\begin{array}{l}\text { With drainage wall, drains effective }(\mathrm{K}=0.37) \text { and uplift under the heel with } \\
\text { the same value as the reservoir level if } \mathrm{n}_{1}<\text { Normal Pool Level, and with an } \\
\text { intermediate value between the reservoir level and the Normal Pool Level } \\
\text { for higher values of } \mathrm{n}_{1} \text {. }\end{array}$ \\
\hline Sediments pressure & $\begin{array}{l}\text { With a specific weight of } 8567 \mathrm{~N} / \mathrm{m}^{3} \text {, height of } 7.75 \mathrm{~m}(257.25 \text { m.a.s.l. }) \text { and } \\
\text { a pressure coefficient of } K_{E}=0.415\end{array}$ \\
\hline
\end{tabular}

In the numerical model environment an alternative definition of the factor of safety is needed. Factor of safety can be defined as the relation between the expected value of the variable and that yielding to failure [32], as it is shown in equation (5).

$$
F S=\frac{\varphi}{\varphi_{\text {fail }}}=\frac{c}{c_{\text {fail }}}
$$

To allow consistent comparison, safety factors defined in this fashion have been calculated for the Base Model (limit equilibrium model) as well. Fig. 11 summarizes the results obtained in terms of factor of safety with both models and Table 12 includes factors of safety and corresponding crack lengths computed for each water level considered.

For the case study, a Level 2 reliability analysis has not been run with the Advanced Model (elastic solid). In this situation, the definition of the performance functions corresponding to the elastic solid model and the limit equilibrium model are essentially different in nature, and therefore, the comparison between the probability values that may be obtained with both models using the Level 2 methods is not meaningful. 
Table 12

Base Model and Advanced Model. Comparison of the factors of safety

\begin{tabular}{|c|c|c|c|c|c|}
\hline \multirow{3}{*}{$\begin{array}{c}\begin{array}{c}\text { Upstream } \\
\text { level } \\
\text { (m.a.s.1.) }\end{array} \\
\mathrm{n}_{1}\end{array}$} & \multicolumn{5}{|c|}{ Factor of Safety, FS } \\
\hline & \multicolumn{3}{|c|}{$\begin{array}{l}\text { A0 - Base Model } \\
\text { (rigid body) }\end{array}$} & \multicolumn{2}{|c|}{$\begin{array}{c}\text { A1 - Advanced Model } \\
\text { (elastic solid) }\end{array}$} \\
\hline & $\mathrm{FS}=\mathrm{g}^{*}+1$ & $\begin{array}{c}\quad \mathrm{FS}= \\
=\varphi / \varphi_{\text {fail }} \\
=\mathrm{c} / \mathrm{c}_{\text {fail }}\end{array}$ & $\begin{array}{c}\text { Crack } \\
\text { length } \\
(\mathrm{m})\end{array}$ & $\begin{array}{c}\text { FS }= \\
=\varphi / \varphi_{\text {fail }} \\
=\mathrm{c} / \mathrm{c}_{\text {fail }}\end{array}$ & $\begin{array}{c}\text { Crack } \\
\text { length } \\
(\mathrm{m})\end{array}$ \\
\hline 268.00 & $>10$ & $>10$ & 0.00 & $>10$ & 0.00 \\
\hline 300.00 & 5.00 & 4.18 & 0.00 & 4.13 & 0.00 \\
\hline 313.00 & 3.11 & 2.64 & 0.00 & 2.61 & 0.00 \\
\hline 320.00 & 2.52 & 2.17 & 0.00 & 1.97 & 5.33 \\
\hline 322.50 & 2.32 & 2.00 & 0.00 & 1.24 & 26.67 \\
\hline 326.00 & 2.07 & 1.79 & 0.00 & $<1.0$ & - \\
\hline 331.70 & 1.78 & 1.56 & 0.00 & $<1.0$ & - \\
\hline
\end{tabular}

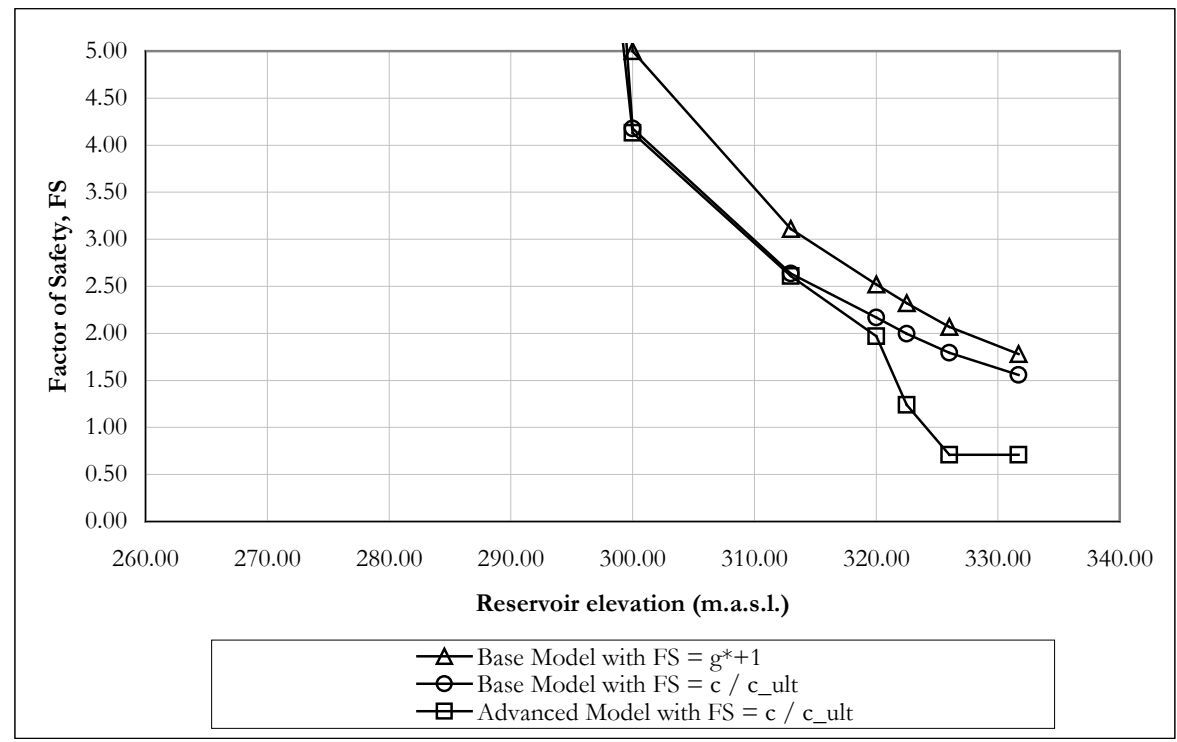

Fig. 11. Base Model and Advanced Model. Comparison of the factors of safety.

The limit curve for the limit equilibrium model with random variables $(\operatorname{tg} \varphi, c)$ is a straight line. If pairs of values $(\operatorname{tg} \varphi, c)$ obtained with the elastic solid model follow a straight line as well, the problem is reduced to a linear regression. Points on the limit surface are estimated by a radial sweep with joint degradation paths with initial points in the boundaries of the feasible region and final point the origin of coordinates. For each water level considered, points are obtained on the limit surface and a line is fitted to them (Fig. 12). The feasible region is defined by (6).

$$
\begin{aligned}
& 30^{\circ} \leq \varphi \leq 70^{\circ} \\
& 0 \leq c \leq 2 \mathrm{MPa}
\end{aligned}
$$




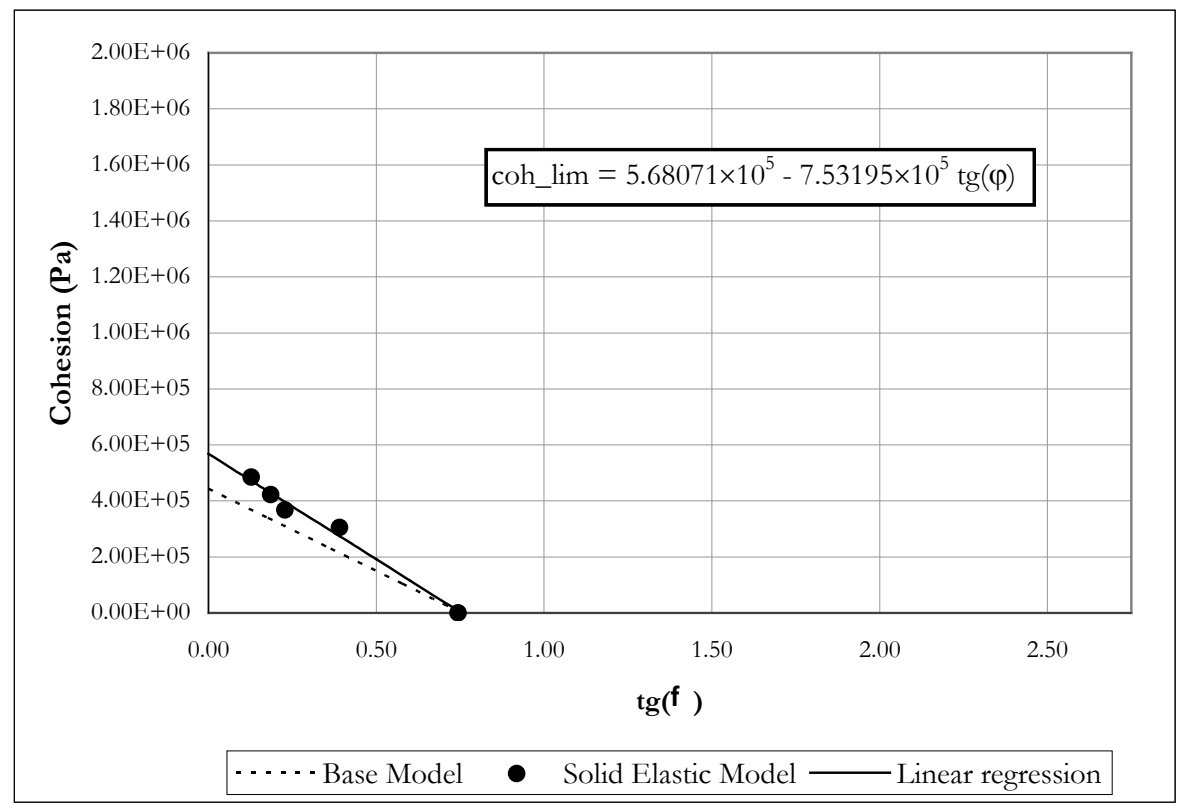

Fig. 12. Adjustment of the limit curve tgழ-c with the elastic solid model. Elevation 320.00 m.a.s.l.

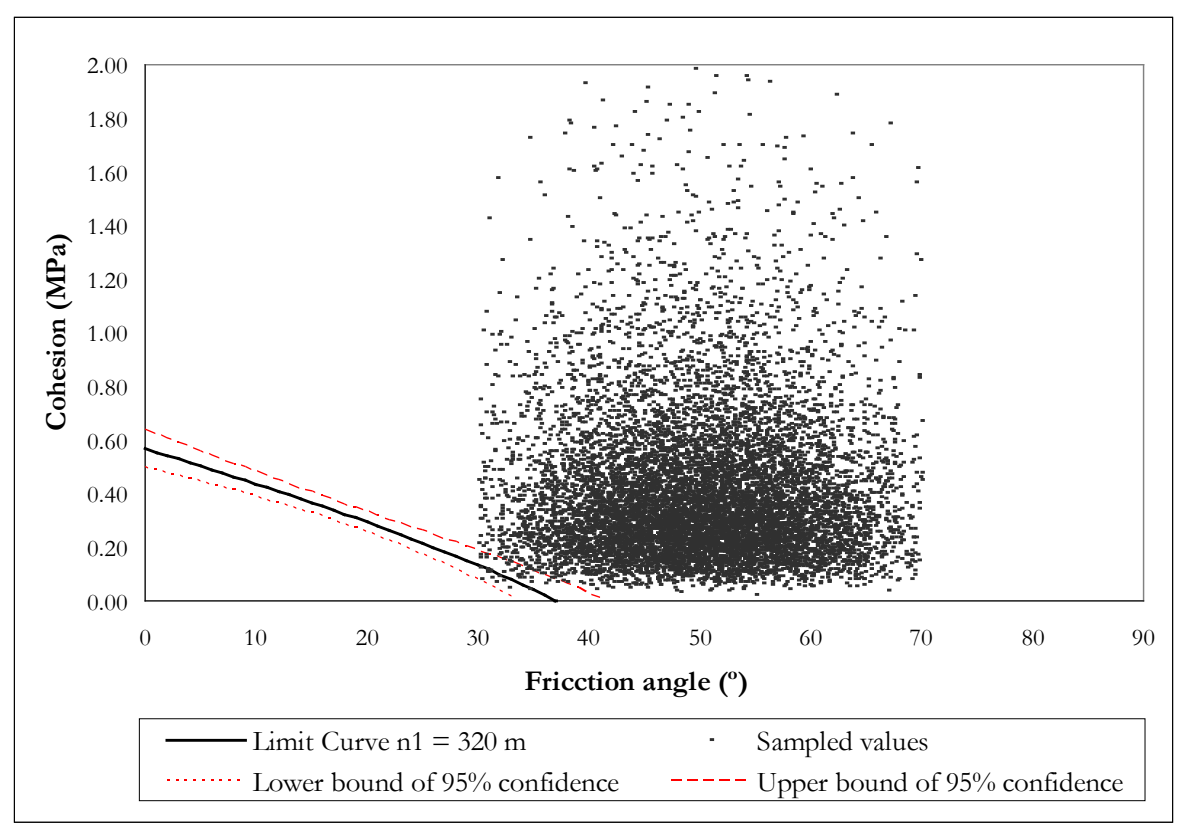

Fig. 13. Monte Carlo method for two random variables without correlation. Limit curve plotted with $90 \%$ confidence intervals. Reservoir elevation of 320.00 m.a.s.l. 
An example of a Monte Carlo simulation is illustrated in Fig. 13. The results obtained using Monte Carlo simulations with the limit curves calculated are shown in Table 13 and in Fig. 14. Note that the Advanced Model, for water level 320 m.a.s.l. (Normal Pool Level), yields a probability of failure of $1.19 \times 10^{-3}$, which is below the all the rest (and similar to the one estimated with the Base Model and Monte Carlo), while for water level 322.50 m.a.s.l. (Crest Level), the probability of failure calculated is $2.25 \times 10^{-1}$, thus showing a strong variation in conditional probability for a small increase in water level.

Table 13

Advanced Model with Level 3 Monte Carlo Method. Probabilities of failure for 2 random variables.

\begin{tabular}{cccccc}
\hline $\begin{array}{c}\text { Upstream } \\
\text { level } \\
\text { (m.a.s.1.) }\end{array}$ & $\begin{array}{c}\text { Downstream } \\
\text { level } \\
\text { (m.a.s.1.) }\end{array}$ & $\begin{array}{c}\text { Number of } \\
\text { samples }\end{array}$ & $\begin{array}{c}\text { Number of } \\
\text { failures }\end{array}$ & $\begin{array}{c}\text { Conditional } \\
\text { probability of } \\
\text { failure }\end{array}$ & $\begin{array}{c}\text { Standard } \\
\text { deviation of } \\
\mathbf{P}_{\mathrm{f}}\end{array}$ \\
\hline $\mathbf{n}_{\mathbf{1}}$ & $\mathbf{n}_{\mathbf{2}}$ & $\mathbf{N}$ & $\mathbf{N}_{\text {fails }}$ & $P_{f}=\frac{N_{\text {fails }}}{N}$ & $\sigma_{\hat{P}_{f}}$ \\
\hline 268.00 & 266.00 & - & - & 0.00 & - \\
300.00 & 266.00 & - & - & 0.00 & - \\
313.00 & 266.00 & $10,000,000$ & 0 & $<1.00 \times 10^{-7}$ & - \\
320.00 & 266.00 & 100,000 & 119 & $1.19 \times 10^{-3}$ & $1.09 \times 10^{-4}$ \\
322.50 & 266.00 & 100,000 & 22,504 & $2.25 \times 10^{-1}$ & $1.32 \times 10^{-3}$ \\
326.00 & 266.00 & - & - & 1.00 & - \\
331.70 & 266.00 & - & - & 1.00 & - \\
\hline
\end{tabular}

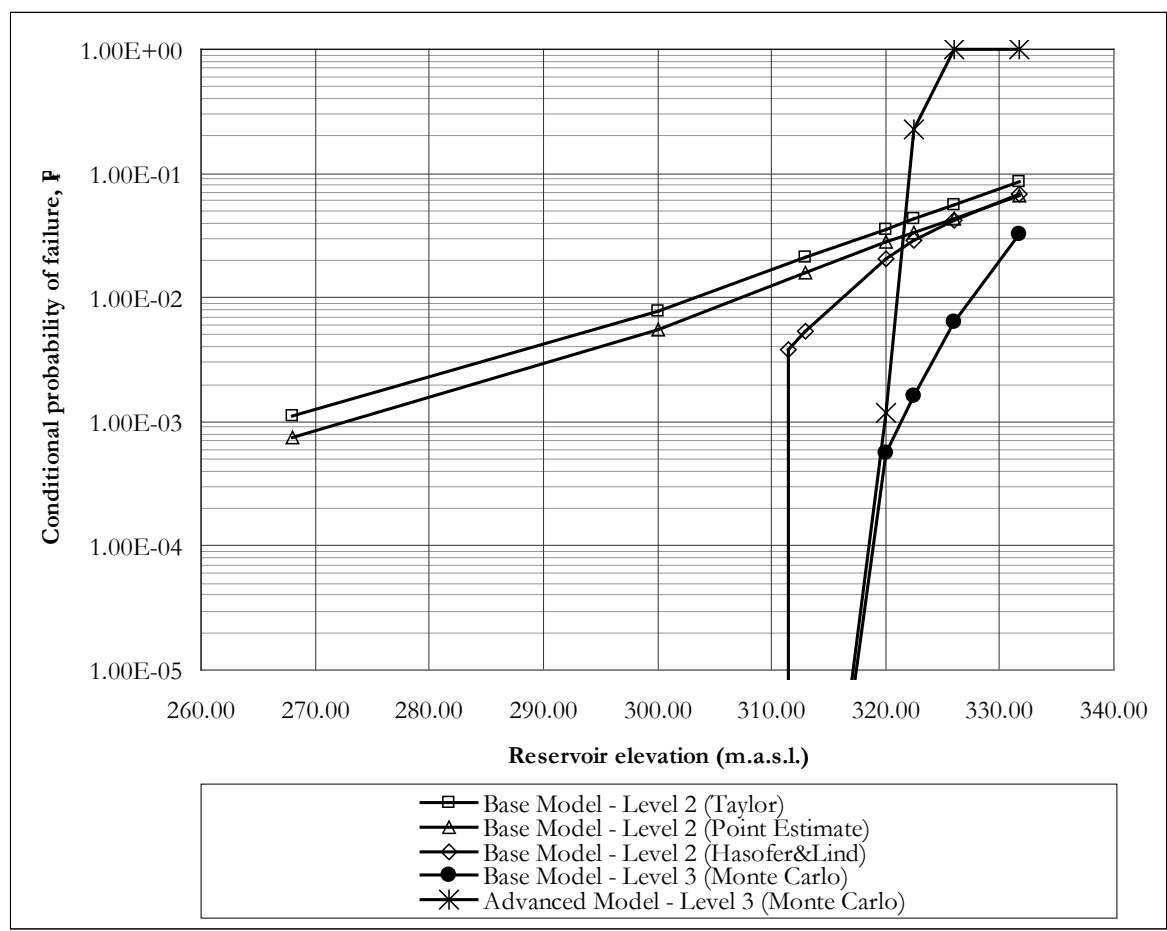

Fig. 14. Probability of failure vs. reservoir elevation. Comparison of values obtained 


\subsection{Interpretation of the results (Step 9)}

From a qualitative point of view, considering the results obtained with the Base Model (limit equilibrium), Level 2 reliability methods provide higher values of the conditional probability of failure than Level 3. Also, it can be seen that the simpler the reliability methods used, the higher the values of the conditional probability of failure obtained. In particular, for the lower reservoir levels, with the exception of ASM, Level 2 methods provide unrealistic values of the probability of failure. ASM Hasofer-Lind provides the best results of all Level 2 methods considered, as they are similar to those from Monte Carlo simulation, which is a more precise method. Level 2 methods seem to systematically overestimate the probability of failure. Refinement of the results is achieved incorporating the Advanced Model in combination with the Monte Carlo techniques. Results show that for the higher water levels (top of the dam and above), the Advanced Model gives the highest probability of failure, while for the lower water levels (below spillway crest), it gives the lowest probability of failure. The reason for this is that the tensile strength in the limit equilibrium model is preventing a crack to develop due to the linear stress distribution hypothesized at the contact plane whereas in the FLAC model the stress concentration at the tip of the crack allows for its propagation. This fact is particularly relevant since it shows that the most simple behavior models may underestimate the probability of failure for high reservoir levels. Factors such as the tensile strength in the interface between dam and foundation and the influence of the "scale effect" on it seem to play a key role [6].

The fact that the simpler reliability techniques seem to overestimate the probability of failure in relation with the more precise Level 3 techniques is very promising in the risk analysis context as its generalization may simplify the task of risk analysts, in the sense that if a gravity dam matches safety criteria in a risk analysis after an evaluation with Level 2 methods, then it would be justified not to conduct further, costly and time-demanding analysis with Level 3 methods.

From a quantitative point of view, the conditional probability obtained does not provide much information on dam safety as it has to be multiplied by the probability of the loadings. To help interpretation of results, a plot of factor of safety against the conditional probability of failure is given on Fig. 15. The results show that even for large factors of safety, the conditional probabilities obtained with the limit equilibrium model in combination with the Level 2 reliability methods are in the order of 0.01 . Even the Advanced Model together with Monte Carlo method shows a probability as high as 0.1 for a factor of safety of 1.5. These rather high values of the conditional probability show that large uncertainties are controlling the results, no matter what model or reliability method is being used. To check the impact of these uncertainties, calculations of conditional probability of failure have been repeated lowering the standard deviation values of friction angle and cohesion, according to Table 14, and thus reducing the coefficients of the variation $(\mathrm{COV})$ of the random variables $(\mathrm{COV}$ is the ratio between standard deviation and mean). For the friction angle the value of the coefficient of variation is lowered from 0.18 to 0.10 and for the cohesion it is lowered from 0.71 to 0.45 , which are typical values found when more than a few data are available from the dam site [33]. As it is shown in Fig. 16 the reduction of uncertainties in the parameters has a strong impact on the estimated probabilities of failure. A reduction of the standard deviation of the $40 \%$ diminishes de probability of failure in at least one order of magnitude. For the Base Model the lower factor of safety obtained is $>1.5$ so the curves can not be plotted below this value. 
Table 14

Two random variables considered. Values with lower coefficients of variation

\begin{tabular}{ccccccc}
\hline Variable & Unit & Prob. Fun & Mean & St. Dev & Min & Max \\
\hline Friction angle $(\varphi)$ & $\circ$ & Normal & 50 & 5.00 & 30 & 70 \\
Cohesion $(\mathrm{c})$ & $\mathrm{MPa}$ & Lognormal & 0.418 & 0.188 & 0.00 & 2.00 \\
\hline
\end{tabular}

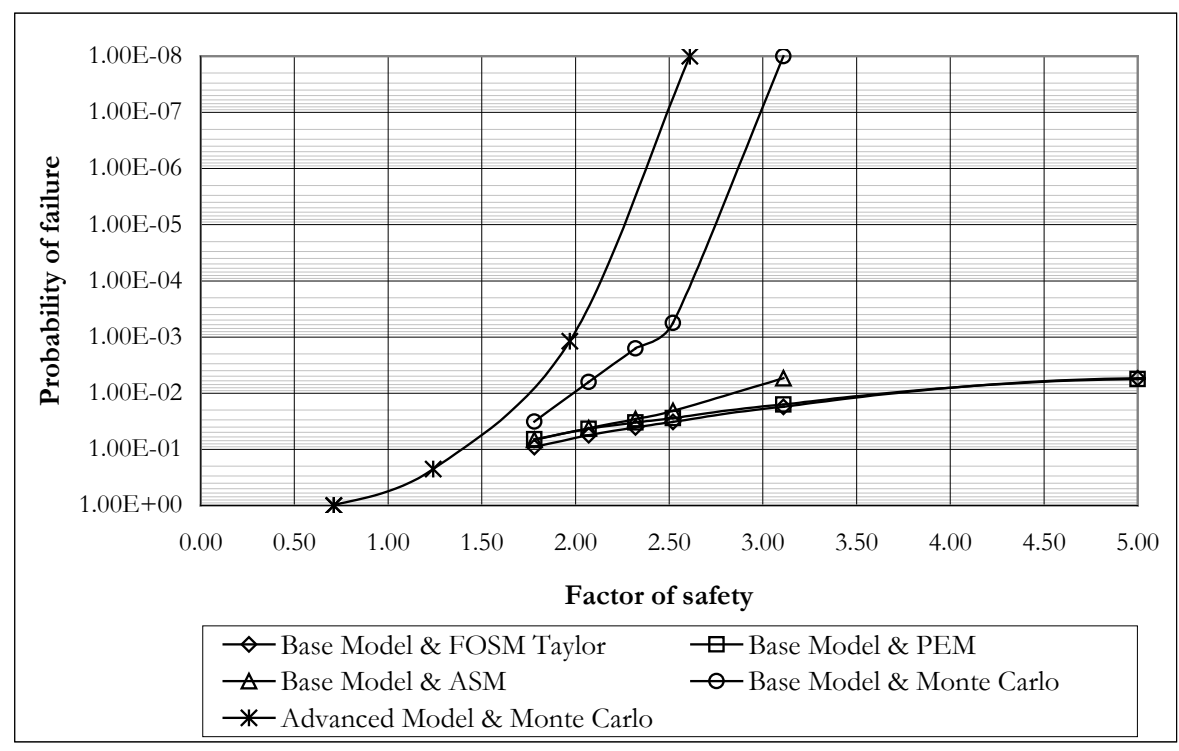

Fig. 15. Factor of safety vs. probability of failure

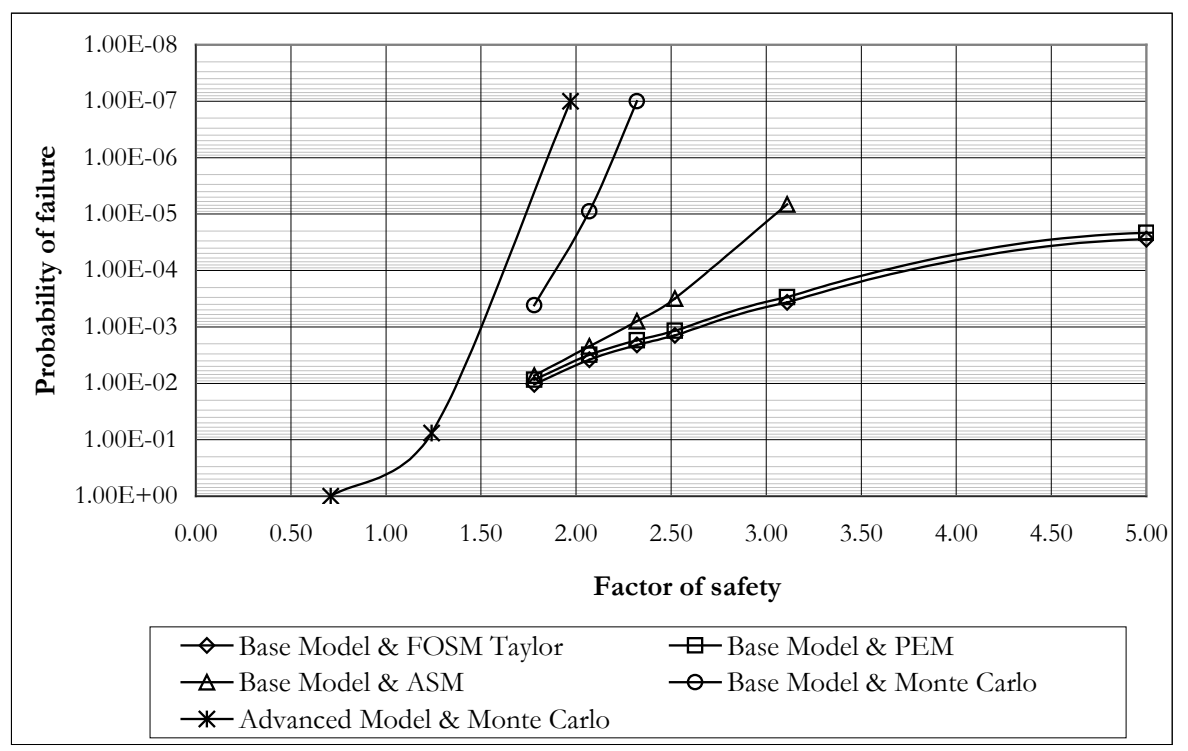

Fig. 16. Factor of safety vs. probability of failure with lower COV's 
Due to the large scatter in the results obtained it would be interesting to evaluate the effect of this variability on the global results in terms of risk and what impact it may have on the decisions related with the dam safety. With this purpose, the UPV research group is developing a new specific software [34] for risk calculations considering the complete risk model of the dam. A summary of all the results obtained is given in Tables 15 and 16 .

\section{Table 15}

Conditional probability of failure with $\mathrm{COV}=0.18$ for friction angle and $\mathrm{COV}=0.71$ for cohesion

\begin{tabular}{ccccccccc}
\hline $\begin{array}{c}\text { Upstream } \\
\text { level } \\
\text { (m.a.s.1.) }\end{array}$ & $\begin{array}{c}\text { AEP } \\
(\mathbf{1} / \mathbf{y r})\end{array}$ & \multicolumn{7}{c}{ Base Model } \\
\hline $\mathbf{n}_{\mathbf{1}}$ & & FS & FOSM & PEM & ASM & $\begin{array}{c}\text { Monte } \\
\text { Carlo }\end{array}$ & FS & $\begin{array}{c}\text { Monte } \\
\text { Carlo }\end{array}$ \\
\hline 268.00 & 1.0 & $>10$ & $1.13 \times 10^{-3}$ & $7.44 \times 10^{-4}$ & 0.00 & 0.00 & $>10$ & 0.00 \\
300.00 & $8.01 \times 10^{-1}$ & 4.18 & $7.73 \times 10^{-3}$ & $5.58 \times 10^{-3}$ & 0.00 & 0.00 & 4.13 & 0.00 \\
313.00 & $5.56 \times 10^{-1}$ & 2.64 & $2.10 \times 10^{-2}$ & $1.59 \times 10^{-2}$ & $5.40 \times 10^{-3}$ & $1.00 \times 10^{-7}$ & 2.61 & $1.00 \times 10^{-7}$ \\
320.00 & $3.57 \times 10^{-1}$ & 2.17 & $3.58 \times 10^{-2}$ & $2.79 \times 10^{-2}$ & $2.08 \times 10^{-2}$ & $5.60 \times 10^{-4}$ & 1.97 & $1.19 \times 10^{-3}$ \\
322.50 & $3.23 \times 10^{-4}$ & 2.00 & $4.26 \times 10^{-2}$ & $3.31 \times 10^{-2}$ & $2.89 \times 10^{-2}$ & $1.60 \times 10^{-3}$ & 1.24 & $2.25 \times 10^{-1}$ \\
326.00 & $1.20 \times 10^{-6}$ & 1.79 & $5.52 \times 10^{-2}$ & $4.29 \times 10^{-2}$ & $4.20 \times 10^{-2}$ & $6.30 \times 10^{-3}$ & $<1.0$ & 1.00 \\
331.70 & $4.00 \times 10^{-9}$ & 1.56 & $8.45 \times 10^{-2}$ & $6.64 \times 10^{-2}$ & $6.78 \times 10^{-2}$ & $3.20 \times 10^{-2}$ & $<1.0$ & 1.00 \\
\hline
\end{tabular}

Table 16

Conditional probability of failure with $\mathrm{COV}=0.10$ for friction angle and $\mathrm{COV}=0.45$ for cohesion

\begin{tabular}{|c|c|c|c|c|c|c|c|c|}
\hline \multirow{2}{*}{$\begin{array}{c}\begin{array}{c}\text { Upstream } \\
\text { level } \\
\text { (m.a.s.1.) }\end{array} \\
\mathrm{n}_{1}\end{array}$} & \multirow[t]{2}{*}{ AEP } & \multicolumn{5}{|c|}{ Base Model } & \multicolumn{2}{|c|}{ Advanced Model } \\
\hline & & FS & FOSM & PEM & ASM & $\begin{array}{c}\text { Monte } \\
\text { Carlo }\end{array}$ & FS & $\begin{array}{c}\text { Monte } \\
\text { Carlo }\end{array}$ \\
\hline 268.00 & 1.0 & $>10$ & $1.59 \times 10^{-7}$ & $1.13 \times 10^{-7}$ & 0.00 & 0.00 & $>10$ & 0.00 \\
\hline 300.00 & $8.01 \times 10^{-1}$ & 4.18 & $2.80 \times 10^{-5}$ & $2.16 \times 10^{-5}$ & 0.00 & 0.00 & 4.13 & 0.00 \\
\hline 313.00 & $5.56 \times 10^{-1}$ & 2.64 & $3.69 \times 10^{-4}$ & $2.98 \times 10^{-4}$ & $6.72 \times 10^{-6}$ & $<10^{-7}$ & 2.61 & $<10^{-7}$ \\
\hline 320.00 & $3.57 \times 10^{-1}$ & 2.17 & $1.41 \times 10^{-3}$ & $1.17 \times 10^{-3}$ & $3.13 \times 10^{-4}$ & $<10^{-7}$ & 1.97 & $1.00 \times 10^{-7}$ \\
\hline 322.50 & $3.23 \times 10^{-4}$ & 2.00 & $2.10 \times 10^{-3}$ & $1.73 \times 10^{-3}$ & $7.90 \times 10^{-4}$ & $1.00 \times 10^{-7}$ & 1.24 & $7.63 \times 10^{-2}$ \\
\hline 326.00 & $1.20 \times 10^{-6}$ & 1.79 & $3.80 \times 10^{-3}$ & $3.14 \times 10^{-3}$ & $2.22 \times 10^{-3}$ & $9.00 \times 10^{-6}$ & $<1.0$ & 1.00 \\
\hline 331.70 & $4.00 \times 10^{-9}$ & 1.56 & $1.04 \times 10^{-2}$ & $8.65 \times 10^{-3}$ & $7.28 \times 10^{-3}$ & $4.14 \times 10^{-4}$ & $<1.0$ & 1.00 \\
\hline
\end{tabular}

To make a meaningful comparison of the results with several guidelines published [35-37] it would be necessary to calculate the total annualized probability of failure, which is the sum, for all the failure modes and for the different water levels, of the products of the probability of the loading by the conditional probability of failure. According to these guidelines, the individual risk, obtained as the product of the total annualized probability of failure by 1 fatality should be less than $10^{-4}\left(\mathrm{yr}^{-1}\right)$.

Considering the results obtained for the dam of the study case, it would be recommended to increase the amount of information about the condition and strength of the contact plane between dam and foundation before carrying any remedial actions. It would be also recommended to try to keep the water level below the Normal Pool Level until this new information is available to feed the risk model. 
The results of conditional probability obtained should also be put into context bearing in mind the different types of existing uncertainties in the process: (a) the uncertainty associated with the randomness or natural variability, in space and time, of the variables; (b) the epistemic uncertainty on the parameters of the materials derived from the scarce number of available data from the tests; and (c) the epistemic uncertainty associated with the limitations of the models for the accurate representation of reality. While natural variability cannot be reduced, epistemic uncertainty can be reduced increasing the amount of information. The epistemic uncertainty derived from the parameters of the materials is treated formally as if it was related with natural variability, which allows a much easier treatment through statistical tools. A formal, separate treatment of natural variability and epistemic uncertainty can be rather cumbersome [23]. In terms of the epistemic uncertainty derived from the models, it is considered that the numerical model constitutes a better approximation to the observed reality rather than the limit equilibrium model, although the reduction of the associated uncertainty is very difficult to quantify. Also, increasing the number of parameters of the model makes it necessary to provide more information in order to be able to reduce the epistemic uncertainty of the parameters. If the deformable solid model is used with Level 3 reliability methods, it is necessary to add to the previous uncertainties the corresponding to the estimate of the position of the limit curve, whose precision depends on the number of points used in its determination.

It is useful to categorize the uncertainties within a model as aleatory or epistemic to have a clear distinction between the uncertainties that have the potential of being reduced and those which do not [38]. Regarding the model used in the paper, uncertainty in variables such as cohesion and friction angle can be characterized as part epistemic and part aleatory. Epistemic uncertainty is present as long as future testing of specimens retrieved of the dam-foundation contact will bring new data of these variables, and the uncertainty on the form of the statistical models used maybe reduced. In addition, uncertainty on the estimated parameters of the statistical distributions of the variables, such as mean and variance, will be also reduced. Part of the uncertainty will remain on the aleatory side, as long as testing procedures involve errors of measurement.

It should be also kept in mind that future scenarios where the dam may withstand extreme loading conditions, such as a water level higher than the maximum historically registered, would be useful to truncate the lower tail of the distributions of strength variables. This approach is directly linked to the so-called performance-based engineering [39].

\subsection{Sensitivity of the results to variations in distributions}

To show the impact of the selected domain of variation of the parameters, the probability of failure has been calculated shortening the range of variation of the friction angle. Two cases have been analyzed: truncation of the normal distribution of $\varphi$ at $32^{\circ}$ and truncation of the normal distribution of $\varphi$ at $35^{\circ}$. The analysis has been carried out only with Monte Carlo, as Level 2 methods cannot capture correctly the consequences derived from this truncation. To keep the distribution symmetrical the maximum values of the distributions have been truncated to values of $68^{\circ}$ and $65^{\circ}$, respectively. 
Table 17

Conditional probability of failure with different truncations of the normal distribution of friction angle

\begin{tabular}{|c|c|c|c|c|c|c|c|c|}
\hline $\begin{array}{c}\text { Upstream } \\
\text { level } \\
\text { (m.a.s.l.) }\end{array}$ & \multicolumn{4}{|c|}{$\begin{array}{l}\text { Base Model } \\
\text { with } \\
\text { Monte Carlo }\end{array}$} & \multicolumn{4}{|c|}{$\begin{array}{c}\text { Advanced Model } \\
\text { With } \\
\text { Monte Carlo }\end{array}$} \\
\hline $\mathrm{n}_{1}$ & FS & {$\left[30^{\circ} ; 70^{\circ}\right]$} & {$\left[32^{\circ} ; 68^{\circ}\right]$} & {$\left[35^{\circ} ; 65^{\circ}\right]$} & FS & {$\left[30^{\circ} ; 70^{\circ}\right]$} & {$\left[32^{\circ} ; 68^{\circ}\right]$} & {$\left[35^{\circ} ; 65^{\circ}\right]$} \\
\hline 268.00 & $>10$ & 0.00 & 0.00 & 0.00 & $>10$ & 0.00 & 0.00 & 0.00 \\
\hline 300.00 & 4.18 & 0.00 & 0.00 & 0.00 & 4.13 & 0.00 & 0.00 & 0.00 \\
\hline 313.00 & 2.64 & $1.00 \times 10^{-7}$ & 0.00 & 0.00 & 2.61 & $1.00 \times 10^{-7}$ & 0.00 & 0.00 \\
\hline 320.00 & 2.17 & $5.60 \times 10^{-4}$ & $2.00 \times 10^{-7}$ & $1.00 \times 10^{-8}$ & 1.97 & $1.19 \times 10^{-3}$ & $8.00 \times 10^{-7}$ & $1.00 \times 10^{-7}$ \\
\hline 322.50 & 2.00 & $1.60 \times 10^{-3}$ & $9.40 \times 10^{-6}$ & $2.00 \times 10^{-7}$ & 1.24 & $2.25 \times 10^{-1}$ & $1.53 \times 10^{-1}$ & $1.37 \times 10^{-1}$ \\
\hline 326.00 & 1.79 & $6.30 \times 10^{-3}$ & $2.88 \times 10^{-4}$ & $2.14 \times 10^{-5}$ & $<1.0$ & 1.00 & 1.00 & 1.00 \\
\hline 331.70 & 1.56 & $3.20 \times 10^{-2}$ & $5.99 \times 10^{-3}$ & $2.20 \times 10^{-3}$ & $<1.0$ & 1.00 & 1.00 & 1.00 \\
\hline
\end{tabular}

As it is shown, the conditional probabilities of failure are reduced even by several orders of magnitude when the friction angle distribution is truncated, and thus not allowing sampling in the region where are the lower values that predict dam instability. It is concluded that it is extremely important to select adequately the feasible range of variation of the parameters as the impact on calculated probabilities is very strong.

To check the impact of the selection of the type of the distributions, the probability of failure has been calculated changing the distributions of the parameters. Two cases have been analyzed. In the first one both friction angle and cohesion are normally distributed $(\mathrm{N}-\mathrm{N})$. In the second, both friction angle and cohesion are lognormally distributed (LN$\mathrm{LN})$. The mean and standard deviation of the distributions have been kept at their original values. The results are compared with those previously obtained assuming normal distribution for friction angle and lognormal distribution for the cohesion (N-LN).

Table 18

Conditional probability of failure with different distributions of friction angle and cohesion

\begin{tabular}{ccccccccc}
\hline $\begin{array}{c}\text { Upstream } \\
\text { level } \\
\text { (m.a.s.1.) }\end{array}$ & \multicolumn{4}{c}{$\begin{array}{c}\text { Base Model } \\
\text { with } \\
\text { Monte Carlo }\end{array}$} & & & \multicolumn{4}{c}{$\begin{array}{c}\text { Advanced Model } \\
\text { With } \\
\text { Monte Carlo }\end{array}$} \\
\hline $\mathbf{n}_{1}$ & FS & N-LN & N-N & LN-LN & FS & N-LN & N-N & LN-LN \\
\hline 268.00 & $>10$ & 0.00 & 0.00 & 0.00 & $>10$ & 0.00 & 0.00 & 0.00 \\
300.00 & 4.18 & 0.00 & 0.00 & 0.00 & 4.13 & 0.00 & 0.00 & 0.00 \\
313.00 & 2.64 & $1.00 \times 10^{-7}$ & $1.40 \times 10^{-5}$ & $1.00 \times 10^{-8}$ & 2.61 & $1.00 \times 10^{-7}$ & $1.40 \times 10^{-5}$ & $1.00 \times 10^{-8}$ \\
320.00 & 2.17 & $5.60 \times 10^{-4}$ & $7.68 \times 10^{-4}$ & $2.00 \times 10^{-6}$ & 1.97 & $1.19 \times 10^{-3}$ & $1.14 \times 10^{-3}$ & $1.60 \times 10^{-5}$ \\
322.50 & 2.00 & $1.60 \times 10^{-3}$ & $1.74 \times 10^{-3}$ & $3.90 \times 10^{-5}$ & 1.24 & $2.25 \times 10^{-1}$ & $1.55 \times 10^{-1}$ & $1.77 \times 10^{-1}$ \\
326.00 & 1.79 & $6.30 \times 10^{-3}$ & $4.62 \times 10^{-3}$ & $5.47 \times 10^{-4}$ & $<1.0$ & 1.00 & 1.00 & 1.00 \\
331.70 & 1.56 & $3.20 \times 10^{-2}$ & $1.61 \times 10^{-2}$ & $7.80 \times 10^{-3}$ & $<1.0$ & 1.00 & 1.00 & 1.00 \\
\hline
\end{tabular}

As it can be seen, when the distribution of the cohesion is changed to normal keeping the friction angle as normal, the results obtained are very similar. On the other hand, when cohesion is kept lognormal and the friction angle is changed to lognormal, the probability of failure obtained lowers significantly. This confirms the fact that friction angle controls 
the stability of the dam and also shows how sensitive is the probability of failure to small changes in the shape of the probability distribution in the vicinity of the limit surface.

\section{Summary and conclusions}

A systematization of the space related with the safety of concrete gravity dams has been proposed, representing in the $\mathrm{X}$-axis the behavior models of the dam as a function of their increasing complexity and in the $\mathrm{Y}$-axis the probabilistic analysis models according to their increasing precision (Level 1, Level 2 and Level 3). A methodology has been developed for the estimation of the conditional probability of failure in the context of risk analysis. The methodology combines different available methods of deterministic and probabilistic analysis. The main advantages are:

a. The safety coefficient is always obtained (Level 1), in order to compare the results with all the other probabilistic Level 2 and 3 methods.

b. The methodology includes the justified discrimination of the random and non random variables that are part of the problem. The probability distribution functions are allocated in a systematic, reasonable and documented way to the variables selected as random, also including in the natural variability, part of the epistemic uncertainty.

c. An analysis is run to determine the contribution of each random variable to the variance of the performance function, through Level 2 FOSM Taylor's Method.

d. The skewness of the distributions is added to the preliminary results when the Level 2 Point Estimate method is included.

e. The feasible region where the probability of failure is not zero is determined in an efficient way, through the Level 2 ASM Hasofer-Lind Method.

f. All the information associated with the probability distribution functions of the random variables is incorporated, through the use of the adequate statistical tools, to the calculation of the probability of failure using the Monte Carlo simulation method (Level 3).

The methodology proposed has been fully applied to a concrete gravity dam and for the sliding along in the dam-foundation contact plane failure mode. All the steps that the methodology comprises have been developed exhaustively, achieving different estimates of the target conditional probability of failure. These innovative results have a significant relevance and should aid in accomplishing, in the future, a generalization of some of the evident conclusions reached in the case analyzed:

- Once the variables with stronger impact on the problem have been identified, sound and expert engineering judgement is essential to assess the uncertainties related with them, in order to set their probability distributions and their variability.

- Also it is necessary to check carefully for possible correlations between variables. Again, expert engineering judgment plays a key role in this issue.

- The type of dam model selected to run the analysis has also a strong influence on the probabilities of failure. 
- The probabilities should be carefully examined. In particular, the relation between factor of safety and probability of failure can be of help to interpret them correctly.

- It seems that Level 2 methods overestimate systematically the probabilities of failure. The generalization of this finding could benefit the practice of risk analysis by simplifying the analysis. More research is needed on this matter, as it seem that Level 2 methods cannot accurately estimate low probabilities in non linear problems.

- The authors' view on the results of the case study is that the large uncertainties of the parameters would represent a kind of envelope of maximum probabilities of failure for this type of dams. Acquisition of further information would reduce dramatically the estimated probability of failure.

- It also the authors' conclusion that the limit equilibrium model is conservative itself, at least for normal pool levels, and that some research is needed to explore what can be the true meaning of the factor of safety in dam engineering if variability of the parameters is not taken into account in its definition. 


\section{References}

[1] ICOLD - International Commission on Large Dams. Bulletin on Risk Assessment in Dam Safety Management. 2003

[2] ICOLD - International Commission on Large Dams. Guidelines for use of numerical models in dam engineering. Proposal for new bulletin. Ad-Hoc Committee on Computational Aspects. 2004

[3] ICOLD - International Commission on Large Dams. Theme A2 Imminent Flood Failure for a concrete gravity dam. 5th International Benchmark Workshop on Numerical Analysis of Dams. Denver, Colorado. 1999

[4] Jefferson, T. Preliminary report on comparison of codes using various benchmark problems. Task 2.4. Integrity Assessment of Large Dams. NW-IALAD. Cardiff University School of Engineering. 2003

[5] Puntel, E.; Bolzon, G.; Saouma, V. A fracture mechanics based model for joints under cyclic loading. ASCE Journal of Engineering Mechanics 2006; 132:1151-9

[6] Bolzon, G. Collapse mechanisms at the foundation interface of geometrically similar concrete gravity dams. Engineering Structures 2010; 32:1304-11

[7] Li, K.S.; Lumb, P. Probabilistic design of slopes. Canadian Geotechnical Journal, $1974 ; 24: 520-35$.

[8] Alonso, E. Risk analysis of slopes and its application to slopes in Canadian sensitive clays. Geotechnique 1976; 26(3):453-72

[9] Tang, W.H.; Yücemen, M.S.; Ang, A.H-S. Probability based short term design of slopes. Canadian Geotechnical Journal, 1976; 13(3):201-15

[10] Christian, J.T.; Ladd, C.C.; Baecher, G.B. Reliability applied to slope stability analysis. Journal of Geotechnical Engineering Division, ASCE 1994; 120(12):2180207

[11] Griffiths, D.V.; Fenton, G.A. Influence of soil strength spatial variability on the stability of an undrained clay slope by finite elements. In Slope Stability 2000, Proceedings of GeoDenver 2000, pages 184-193. ASCE 2000

[12] Husein, A.I.; Hassan, W.F.; Abdulla, F.A. Uncertainty and reliability analysis applied to slope stability. Structural Safety, 2000; 22:161-87

[13] Griffiths, D.V.; Fenton, G.A.; Manoharan, N. Bearing capacity of rough rigid strip footing on cohesive soil: probabilistic study. Journal of Geotechnical and Geoenvironmental Engineering, September 2002; 128(9):743-55

[14] Fenton, G.A.; Griffiths, D.V.; Williams, M.B. Reliability of traditional retaining wall design. Geotechnique 2005; 55(1):55-62

[15] Marco, C. Crack models in concrete dams. Colegio de Ingenieros de Caminos, Canales y Puertos, 1995. Madrid.

[16] Ghrib, F.; Lèger, P.; Tinawi, R.; Lupien, R. y Veilleux, M. A progressive methodology for seismic safety evaluation of gravity dams: from the preliminary screening to non-linear finite element analysis. The International Journal of Hydropower and Dams, 1998. Issue two pp. 126-138. 
[17] Ruggeri, G.; Pellegrini, R.; Rubin de Célix, M.; Bernsten, M.; Royet, P.; Bettzieche, V.; Amberg, W.; Gustaffson, A.; Morison, T. and Zenz, G. Sliding safety of existing gravity dams. Final report. ICOLD European Club. Working group on sliding safety of existing gravity dams, 2004.

[18] Cornell, C.A. First order uncertainty analysis of soils deformation and stability. Proceedings 1st Int. Conf. On Application of Probability and Statistics in Soil and Structural Engineering Hong Kong, 1971. p.129-44.

[19] Rosenblueth, E. Two-point estimates in probabilities. Applied mathematical modelling, 5; 1981

[20] Christian, J.T.; Baecher, G.B. The point-estimate method with large numbers of variables. International Journal for Numerical and Analytical Methods in Geomechanics, 2002; 26:1515-29

[21] Hasofer, A.M.; Lind, N.C. (1974). Exact and invariant second moment code format. Journal of Engineering Mechanics, 1974; 100, EM1, 111-121

[22] Tobutt, D.C. Monte Carlo simulation methods for slope stability. Computer and Geosciences, 1982; 8(2):199-208.

[23] Cho, S.E. Probabilistic stability analyses of slopes using the ANN-based response surface. Computers and Geotechnics, 2009; 36:787-797.

[24] Xu, B.; Low, B.K. Probabilistic stability analysis of embankments based on finite element method. Journal of Geotechnical and Geoenvironmental Engineering, 2006; 132(11):1444-54.

[25] Smith, M. Influence of uncertainty in the stability analysis of a dam foundation. Dam maintenance and rehabilitation; 2003; pages 151-158

[26] Hartford, N.D.; Baecher, B. Risk and uncertainty in dam safety. Thomas Telford Ltd.; 2004

[27] Membrillera, M.G. de . Contribution to the application of risk assessment to Spanish dams. Doctoral thesis. Universidad Politécnica de Valencia, 2007

[28] Altarejos, L. Contribution to the estimation of the probability of failure of concrete gravity dams in the risk analysis context. Doctoral thesis. Universidad Politécnica de Valencia, 2009

[29] Soriano, A.; Sánchez, F.J. Evaluation of safety against foundation failure of concrete dams. Dam safety, 1998; pages 537-544. Ed. Berga, L. Balkema, Rotterdam.

[30] Hoek, E. Practical Rock Engineering. On-line course, 2007

[31] Krounis, A.; Johansson, F. The influence of correlation between cohesion and friction angle on the probability of failure for sliding of concrete dams. Risk analysis, dam safety, dam security and critical infrastructure management. 2011. Ed. Escuder-Bueno, I.; Matheu, E.; Altarejos-García, L. and Castillo-Rodríguez, J.T. CRC Press Inc. / Balkema, Rotterdam.

[32] Serrano, A. Numerical modelling of dam behaviour in the risk analysis context. Universidad Politécnica de Valencia, 2007

[33] Westberg, M. Reliability-based assessment of concrete dam stability. Licenciate 
Thesis. Division of Structural Engineering, Lund Institute of Technology, Lund University. Report TVBK-1033. 2010

[34] Serrano, A.; Escuder, I.; Membrillera, M.G. de; Altarejos, L. iPresas: Software for risk analysis. XXII International Congress on Large Dams. Brasilia, 2009. Brazil.

Con formato: Español (alfab. internacional)

[35] Bureau of Reclamation. Guidelines for achieving public protection in dam safety decision making. Technical Report, U.S. Department of the Interior, 2003

[36] Australian Committee on Large Dams. Guidelines on Risk Assessment, 2003

[37] Munger, D.F.; Bowles, D.S.; Boyer, D.D.; Davis, D.W.; Margo, D.A.; Moser, D.A.; Regan, P.J., Snorteland, N. Interim tolerable risk guidelines for US Army Corps of Engineering dams. USSD Workshop on the future of dam safety decision making: combining standards and risk. 2009

[38] Der Kiureghian, A.; Ditlevsen, O. Aleatory or epistemic? Does it matter?. Special workshop on risk acceptance and risk communication. March 26-27. Stanford University.

[39] Wen, Y.K. Reliability and performance-based design. Structural Safety, 2001; 23:407-28 